\title{
Nitric Oxide Mediates Activity-Dependent Plasticity of Retinal Bipolar Cell Output via S-Nitrosylation
}

\author{
Ryan E. Tooker, ${ }^{1}$ Mikhail Y. Lipin, ${ }^{1}$ Valerie Leuranguer, ${ }^{1}$ Eva Rozsa, ${ }^{1}$ Jayne R. Bramley, ${ }^{1}$ Jacqueline L. Harding, ${ }^{2}$ \\ Melissa M. Reynolds, ${ }^{2}$ and Jozsef Vigh $^{1}$ \\ ${ }^{1}$ Department of Biomedical Sciences and ${ }^{2}$ Department of Chemistry, Colorado State University, Ft. Collins, Colorado 80523
}

Coding a wide range of light intensities in natural scenes poses a challenge for the retina: adaptation to bright light should not compromise sensitivity to dim light. Here we report a novel form of activity-dependent synaptic plasticity, specifically, a "weighted potentiation" that selectively increases output of Mb-type bipolar cells in the goldfish retina in response to weak inputs but leaves the input- output ratio for strong stimuli unaffected. In retinal slice preparation, strong depolarization of bipolar terminals significantly lowered the threshold for calcium spike initiation, which originated from a shift in activation of voltage-gated calcium currents $\left(\mathrm{I}_{\mathrm{Ca}}\right)$ to more negative potentials. The process depended upon glutamate-evoked retrograde nitric oxide (NO) signaling as it was eliminated by pretreatment with an NO synthase blocker, TRIM. The NO-dependent $\mathrm{I}_{\mathrm{Ca}}$ modulation was cGMP independent but could be blocked by $N$-ethylmaleimide (NEM), indicating that NO acted via an S-nitrosylation mechanism. Importantly, the NO action resulted in a weighted potentiation of Mb output in response to small $\left(\leq-30 \mathrm{mV}\right.$ ) depolarizations. Coincidentally, light flashes with intensity $\geq 2.4 \times 10^{8}$ photons $/ \mathrm{cm}^{2} / \mathrm{s}$ lowered the latency of scotopic $\left(\leq 2.4 \times 10^{8}\right.$ photons $\left./ \mathrm{cm}^{2} / \mathrm{s}\right)$ light-evoked calcium spikes in Mb axon terminals in an NEM-sensitive manner, but light responses above cone threshold $\left(\geq 3.5 \times 10^{9}\right.$ photons $\left./ \mathrm{cm}^{2} / \mathrm{s}\right)$ were unaltered. Under bright scotopic/mesopic conditions, this novel form of $\mathrm{Mb}$ output potentiation selectively amplifies dim retinal inputs at $\mathrm{Mb} \rightarrow$ ganglion cell synapses. We propose that this process might counteract decreases in retinal sensitivity during light adaptation by preventing the loss of visual information carried by dim scotopic signals.

\section{Introduction}

The retina codes for contrast, color, and motion information of an image projected to the photoreceptor mosaic (Wässle, 2004) under light intensities changing across 10 orders of magnitude (Dowling, 1987; Sterling, 2003). To fit this wide range of inputs to the output limited by the maximal spiking rate of ganglion cells (GCs) $\left(\sim 10^{2}\right)$, the retina adapts to the average light intensity ("light adaptation") as well as to the range of intensities around the mean ("contrast adaptation") by shifting the dynamic range of coding (Demb, 2002; Rieke and Rudd, 2009). Both light and contrast adaptation are accomplished by implementing various strategies at different stages of retinal processing and on multiple time scales. However, the fundamental challenge for all retinal adaptation processes is similar: prevent saturation of retinal output at high stimulus intensity/contrast while maintaining coding capability for weak inputs.

Contrast adaptation of GC responses is resolved using two opposing forms of plasticity in parallel: after high-contrast stim-

Received July 1, 2013; revised Oct. 23, 2013; accepted 0ct. 31, 2013.

Author contributions: R.E.T., M.Y.L., and J.V. designed research; R.E.T., M.Y.L., V.L., E.R., J.R.B., and J.V. performed research; J.L.H. and M.M.R. contributed unpublished reagents/analytic tools; R.E.T., M.L., V.L., J.L.H., M.M.R., and J.V. analyzed data; R.E.T., M.L., M.M.R., and J.V. wrote the paper.

This work was supported by the National Institutes of Health-National Eye Institute Grant EY019051 to J.V. We thank Shannon K. Gallagher and Vinod Damodaran for their assistance in the completion of this study.

The authors declare no competing financial interests.

Correspondence should be addressed to Dr. Jozsef Vigh, Department of Biomedical Sciences, Colorado State University, Ft. Collins, C0 80523. E-mail: jozsef.vigh@colostate.edu.

DOI:10.1523/JNEUROSCI.2792-13.2013

Copyright $\odot 2013$ the authors $\quad 0270-6474 / 13 / 3319176-18 \$ 15.00 / 0$ ulation, some GC responses were depressed in response to consecutive low-contrast stimuli, whereas others were sensitized (Smirnakis et al., 1997; Kim and Rieke, 2001; Baccus and Meister, 2002; Kastner and Baccus, 2011). In addition to adaptation processes intrinsic to GCs (Kim and Rieke, 2001; Baccus and Meister, 2002), short-term synaptic plasticity mechanisms that affect bipolar cell (BC) output onto GCs also play a critical role in both adaptation and sensitization during contrast adaptation of GCs (Rieke, 2001; Kastner and Baccus, 2011; Nikolaev et al., 2013). To adapt to changing light intensity and sustain vision across all light conditions, the retina uses a highly sensitive rod pathway for night vision and a less sensitive cone pathway for daylight vision (Walraven et al., 1990). The light sensitivities of rods and cones overlap, forming a substantial mesopic range that covers behaviorally relevant environmental light intensities for many vertebrates (Wu, 1994; Krizaj, 2000). The dynamic interaction between the rod and cone pathways is influenced by neuromodulators. For example, during light adaptation, dopamine increases signal flow through cone circuits, diminishes that through rod circuits (Witkovsky, 2004), and reduces GC responses to prevent saturation (Hayashida et al., 2009), which ultimately reduces overall retinal sensitivity.

Here we report a novel form of activity-dependent synaptic plasticity in the retina, mediated by retrograde nitric oxide (NO) signaling. Mbs in the goldfish retina receive and process both rod and cone input (Wong et al., 2005; Joselevitch and Kamermans, 2009). The synaptic plasticity described here results in selective, weighted potentiation of $\mathrm{Mb}$ output in response to weak rod- but 
not cone-mediated inputs. We propose that this new form of NO-mediated, activity-dependent synaptic plasticity plays an important role under bright scotopic and mesopic conditions. Selective enhancement of weak, rod-mediated inputs at the $\mathrm{Mb}$ $\rightarrow$ GC synapses may counteract sensitivity loss during light adaptation, ultimately preventing the loss of visual information carried by low-intensity signals. Our results suggest that, similar to contrast adaptation (Kastner and Baccus, 2011), adaptation to increasing luminance also uses opposing forms of plasticity in parallel to extend the dynamic range of retinal signaling.

\section{Materials and Methods}

\section{Retinal preparations}

Retinal slices and isolated bipolar cells were prepared from retinal tissue dissected from adult 4- to 5-inch-long Goldfish (Carassius auratus) of either sex that had been dark-adapted for at least $1 \mathrm{~h}$. Goldfish were kept on a $12 \mathrm{~h} \mathrm{light/dark} \mathrm{schedule.} \mathrm{All} \mathrm{experimental} \mathrm{procedures} \mathrm{conformed} \mathrm{to}$ the guidelines of the Colorado State University Institutional Animal Care and Use Committee.

Retinal slice preparation. Retinal slices $(200-250 \mu \mathrm{m})$ were prepared as described previously (Palmer et al., 2003). In experiments requiring light stimulation, slice preparation and dissection procedures were performed under infrared illumination as previously described (Vigh et al., 2011). After the slicing procedure, slices in the recording chamber were moved to an upright microscope (Axioskop 2, Zeiss) and superfused at 2-5 $\mathrm{ml} / \mathrm{min}$ with Ringer's solution containing the following (in $\mathrm{mM}$ ): 100 $\mathrm{NaCl}, 2.5 \mathrm{KCl}, 1.0 \mathrm{MgCl}_{2}, 2.5 \mathrm{CaCl}_{2}, 25 \mathrm{NaHCO}_{3}, 0-0.2$ ascorbic acid, and 12 glucose or with bicarbonate buffered Ames' medium (US Biological) supplemented with $1.15 \mathrm{~mm} \mathrm{CaCl}$. The $\mathrm{pH}$ was set to 7.45 with $\mathrm{NaOH}$. The osmolarity was $260 \pm 2 \mathrm{mOsmol}$ for both Ringer's solution and Ames' medium, and both were gassed continuously with $95 \% \mathrm{O}_{2} / 5 \%$ $\mathrm{CO}_{2}$. To block inhibitory feedback to $\mathrm{Mb}$ terminals, picrotoxin (PTX, $100 \mu \mathrm{M}$ ) was present (Vigh et al., 2005, 2011) in all retinal slice experiments unless otherwise noted. Slices were viewed using a $40 \times$ waterimmersion objective and infrared differential contrast and through an infrared CCD camera with 2.5 premagnification (XC-75, Sony). The camera was connected to a Camera Controller C2741-62 (Hamamatsu), which directed the output to a 19 inch monitor (Westinghouse). Identification of $\mathrm{Mb}$ terminals within the inner plexiform layer was based on the large, bulbous terminal morphology and $\mathrm{C}_{\mathrm{m}}$ increase after depolarization (Palmer et al., 2003).

Dissociated $M b$ preparation. Solitary bipolar cells were isolated by conventional methods (Tachibana and Kaneko, 1987). Briefly, retinal pieces were dissociated by mechanical trituration with a Pasteur pipette after papain digestion (10 U/ml, Worthington Biochemical). Dissociated cells were plated on clean glass bottom dishes (MatTek) coated with poly-Dlysine, and stored at room temperature in low $\mathrm{Ca}^{2+}(0.2 \mathrm{~mm} \mathrm{CaCl})$ Ringer's solution containing the following (in $\mathrm{mm}$ ): $117 \mathrm{NaCl}, 2.6 \mathrm{KCl}$, $1.0 \mathrm{MgCl}_{2}, 0.2 \mathrm{CaCl}_{2}, 10$ glucose, 5 HEPES, and supplemented with 0.5 $\mathrm{mg} / \mathrm{ml}$ BSA. The $\mathrm{pH} 7.45$ was set with $\mathrm{NaOH}$; osmolarity was $260 \pm 2$ mOsmol. Plated cells were viewed using DIC optics through a $40 \times$ air objective coupled to a $2.5 \times$ Optovar cube (Axio Observer Z1; Zeiss) and AxioCam HRm CCD camera (Zeiss) and were superfused at $2-5 \mathrm{ml} / \mathrm{min}$ with Ringer's solution (see above).

\section{Electrophysiology and light stimulation}

Whole-cell voltage- and current-clamp recordings were made directly from $\mathrm{Mb}$ terminals in both slice and dissociated preparations using a EPC-10 USB patch-clamp amplifier and Patchmaster software (version 2.3; both HEKA) at room temperature during daytime (10 A.M. to 6 P.M.). Membrane current and voltage data were filtered at $3 \mathrm{kHz}$, sampling rates were set at $5 \mathrm{kHz}$ for voltage ramp protocols, $20 \mathrm{kHz}$ for voltage step protocols, and $25 \mathrm{kHz}$ for recording spiking membrane potential responses in either current-clamp ramp protocol or using light stimulation. The current-clamp ramp protocol used in these studies stretched from $-20 \mathrm{pA}$ to $65 \mathrm{pA}$ over $2 \mathrm{~s}$ and was applied relative to the holding current that kept the resting membrane potential at $-60 \mathrm{mV}$. The holding current was determined in voltage-clamp mode when estab- lishing whole-cell mode ("patch break") and was maintained when switching to current-clamp mode using the "Gentle CC-switch" option of Patchmaster. The threshold of current ramp-evoked spikes was determined as follows: The leak was estimated based on the slope of the membrane voltage trace between $-100 \mathrm{mV}$ and $-60 \mathrm{mV}$. The leak-subtracted data were normalized to the first (initial) spike amplitude. A current ramp-evoked membrane potential change was considered a spike if its peak voltage exceeded $2 \mathrm{SD}$ of the baseline noise between $-100 \mathrm{mV}$ and $-60 \mathrm{mV}$. The threshold was defined as $5 \%$ of the peak membrane voltage for the first spike. Current-voltage relationships were determined by whole-cell voltage-clamp ramps and conventional stepwise reconstructions. The whole-cell voltage-clamp ramp protocol used in these studies was a linear $2 \mathrm{~s}$ ramp from -100 to $50 \mathrm{mV}$. The stepwise I-V protocol consisted of $3 \mathrm{~ms}$ steps to potentials (from $-80 \mathrm{mV}$ to $60 \mathrm{mV}, 10 \mathrm{mV}$ increments) with $5 \mathrm{~s}$ between each step. For real-time measurement of membrane capacitance, the Sine +DC technique was used (Gillis, 2000). The capacitive current was measured by the lock-in amplifier after a 1 $\mathrm{kHz}$ sinusoidal voltage command (20 $\mathrm{mV}$ peak to peak) applied to the holding potential of $-60 \mathrm{mV}$. Patch pipettes of $8-12 \mathrm{M} \Omega$ were pulled using a horizontal puller (model p-97, Sutter) from 1.5-mm-diameter, thick-walled borosilicate glass (World Precision Instruments) and were coated with dental wax (Cavex) to reduce stray pipette capacitance. For isolation of $\mathrm{I}_{\mathrm{Ca}}$ in whole-cell voltage-clamp experiments, a Cs-gluconatebased internal solution was used (in $\mathrm{mm}$ ) as follows: 85 Cs-gluconate, 10 phosphocreatine-di(tris) salt, 10 L-ascorbic acid, 10 TEA-Cl, 10 methylamine $\mathrm{HCl}, 2$ EGTA, 3 Mg-ATP, $0.5 \mathrm{Na}-\mathrm{GTP}, \mathrm{pH} 7.2$ (adjusted with $\mathrm{CsOH}$ ), and osmolarity of $260 \pm 2 \mathrm{mOsmol}$. For current-clamp (including light-evoked response) recordings, a K-gluconate based internal was used (in $\mathrm{mm}$ ) as follows: $106 \mathrm{~K}$-gluconate, 10 phosphocreatine-di(tris), 3 L-ascorbic acid, $10 \mathrm{KCl}, 3 \mathrm{Mg}$-ATP, 2 EGTA, 0.5 Na-GTP, pH 7.2 (adjusted with $\mathrm{NaOH}$ ), and osmolarity of $260 \pm 2 \mathrm{mOsmol}$. During experiments using BAPTA, Exo 1, KT5823, or N-ethylmaleimide (NEM) in the pipette solution, at least $1 \mathrm{~min}$ was allowed for intracellular perfusion with the pipette solution before any recording and at least $45 \mathrm{~s}$ with standard pipette solution. To keep the osmolarity constant, when $10 \mathrm{~mm}$ BAPTA was included in the pipette solution, the amount of Cs-gluconate was reduced accordingly.

In voltage-clamp experiments voltage commands were not corrected for liquid junction potential. Series resistance (Rs) was tightly monitored during recording and was not compensated electronically. Data obtained from $\mathrm{Mb}$ terminals were excluded if the uncompensated Rs exceeded 30 $\mathrm{M} \Omega$, as in such recordings we found the slope of $\mathrm{I}_{\mathrm{Ca}}$ activation curve to exceed 1/Rs indicating the lack of voltage-clamp (Marty and Neher, 1995). Rs change by $20 \%$ any time during the recording also resulted in exclusion of the recording from further evaluation. Recordings with greater than $\pm 1 \mathrm{mV}$ drift of electrode potential, measured at the beginning and conclusion of the recording, were also excluded. Light stimulation was performed as previously described (Vigh et al., 2011). Briefly, 500 -ms-long green $(\lambda=505 \mathrm{~nm})$ or red $(\lambda=660 \mathrm{~nm})$ LEDs (American Bright Optoelectronics) were used for full-field illumination of retinal slices. The LED voltage was controlled by the EPC-10 through D/A output. The light intensity was calibrated with an optical meter (model 1918-C, sensor 918D-SL-OD3; Newport).

\section{Drugs and chemicals}

Kainic acid (KA), NBQX, D-(-)-2-amino-5-phosphonopentanoic acid (D-AP5), 1-(2-trifluromethylphenyl)imidazole (TRIM), 8-bromoguanosine cyclic 3', 5'-monophosphate sodium salt (8-Br-cGMP), Exo 1, KT5823, and picrotoxin were obtained from Tocris Bioscience. All other chemicals and salts were obtained from Sigma.

Diethyltriamine-NO/NO (DETA/NO) was synthesized and validated as an NO donor as previously described (Maragos et al., 1991; Hrabie et al., 1993; Damodaran et al., 2012). Briefly, $500 \mathrm{mg}$ of diethyltriamine was added to a thick-walled glass reaction vessel equipped with a stir bar. The vessel contained $40 \mathrm{ml}$ of dehydrated acetonitrile dried over $40 \mathrm{~nm}$ molecular sieves. The reaction vessel was capped with a gas tight lid and was attached to a custom-made NO reactor. Oxygen was flushed from the reaction vessel using argon purges. $\mathrm{NO}$ was introduced to the vessel and kept at a pressure of $80 \mathrm{psi}$ for $24 \mathrm{~h}$ under stirring conditions. The result- 
ing white DETA/NO precipitate was collected by filtration, washed with acetonitrile, and dried under vacuum. The DETA/NO was then validated by a characteristic UV absorbance feature at $252 \mathrm{~nm}$ in $0.01 \mathrm{M} \mathrm{NaOH}$ with a molar extinction coefficient of $7600 \mathrm{M}^{-1} \mathrm{~cm}^{-1}$. Direct and real-time NO measurements were performed using GE Analytical Nitric Oxide Analyzer equipped with a custom sample cell. A $3 \mathrm{ml}$ aliquot of the media containing DETA/NO was added to the sample cell. The temperature of the sample cell was maintained at $21^{\circ} \mathrm{C}$. Measurements were collected at $5 \mathrm{~s}$ intervals at the following instrument operating parameters: cell pressure $(1.37 \mathrm{kPa})$, supply pressure $(38.6 \mathrm{kPa})$, and cooler temperature $\left(-12^{\circ} \mathrm{C}\right)$. The DETA solution was prepared $20 \mathrm{~min}$ before evaluation. Upon injection into the NOA sample cell, NO release with a steady rate was observed for the duration of the measurement. An average NO release rate of $2.00 \pm 0.19 \mathrm{nM} \mathrm{s}^{-1}$ was measured $(n=4)$. This value corresponds to an average instantaneous concentration of NO of $9.99 \pm$ $0.93 \mathrm{nM}$, which matches retinal NO concentrations measured extracellularly 10-20 $\mu \mathrm{m}$ away from relatively strong sources of NO production (Eldred and Blute, 2005). In all of our experiments, the DETA/NO solution $(1 \mathrm{mM})$ was made fresh every day at least $1 \mathrm{~h}$ before the experiment began and used for a maximum of $12 \mathrm{~h}$.

Data analysis

All data were analyzed off-line using IgorPro software (version 5.03; Wavemetrics). Voltage-clamp ramp and stepwise I-V curves were leaksubtracted and normalized to the peak to analyze the $\mathrm{Ca}^{2+}$ or $\mathrm{K}^{+}$currents. Estimation of the leak current was accomplished using a procedure similar to that reported by Hirasawa and Kaneko (2003). The leak subtraction procedure consisted of extrapolating the slope of the line between $-100 \mathrm{mV}$ and $-60 \mathrm{mV}$. The estimated leak current was subtracted from the raw value providing the "pure" $\mathrm{I}_{\mathrm{Ca}}$ or $\mathrm{I}_{\mathrm{K}}$. Normalized, leaksubtracted ramp-evoked $\mathrm{I}_{\mathrm{K}} \mathrm{I}-\mathrm{V}$ curves were fit using the following Boltzmann equation:

$$
\mathrm{I}=1 /\left\{1+\exp \left[\left(\mathrm{V}-\mathrm{V}_{1 / 2}\right) / \mathrm{S}\right]\right\}
$$

where $\mathrm{V}_{1 / 2}$ is the half-activation potential and $\mathrm{S}$ is the slope of the voltage dependency (Griguer and Fuchs, 1996). For the stepwise $\mathrm{I}_{\mathrm{Ca}} \mathrm{I}-\mathrm{V}$ curve, the first 3 points $(-80,-70,-60 \mathrm{mV})$ were used to estimate the leak current for extrapolation. Leak-subtracted stepwise and ramp-evoked $\mathrm{I}_{\mathrm{Ca}} \mathrm{I}-\mathrm{V}$ curves were fit using the following modified Boltzmann equation:

$$
\mathrm{I}=\mathrm{G}_{\max } \times\left(\mathrm{V}-\mathrm{V}_{\text {rev }}\right) /\left\{1+\exp \left[-\left(\mathrm{V}-\mathrm{V}_{1 / 2}\right) / \mathrm{k}_{\mathrm{G}}\right]\right\},
$$

where $V_{\text {rev }}$ is the reversal potential, $G_{\max }$ is the maximum $\mathrm{Ca}^{2+}$ conductance, $\mathrm{V}_{1 / 2}$ is the half-activation potential, and $\mathrm{k}_{\mathrm{G}}$ is the slope factor (Leuranguer et al., 2003). Curve fits were done using SigmaPlot (version 11; Systat Software). For ramp evoked $\mathrm{I}_{\mathrm{Ca}} \mathrm{I}-\mathrm{V}$ data, analysis of I-V kinetics was also determined directly by using MiniAnalysis software (version 6.0.3; Synaptosoft). "Activation" $\left(\mathrm{V}_{(5 \%)}\right)$ was defined as the voltage at which the resulting current was $5 \%$ of the peak current, "half-activation" $\left(\mathrm{V}_{(50 \%)}\right)$ was defined as the voltage at which the resulting current was halfway between "activation" and the peak current, and "maximum" $\left(\mathrm{V}_{(\text {Max })}\right)$ was defined as the voltage that resulted in the peak current.

Threshold of calcium spikes, in current-clamp ramp protocols, was determined using baseline-subtracted and normalized recordings. A baseline subtraction procedure similar to that used for voltage clamp was implemented for the current-clamp recordings. Then, the data were normalized to first (initial) spike amplitude. For light-evoked spikes, the latency to first spike was determined by the time point corresponding to the peak of the first evoked spike relative to the onset of the light stimulus. Where appropriate, depolarization triggered transmitter release was calculated based on the increase in membrane capacitance $\left(C_{m}\right.$ jump or $\Delta \mathrm{C}_{\mathrm{m}}$ ) by the equation $\Delta \mathrm{C}_{\mathrm{m}}=\mathrm{C}_{\mathrm{m}}$ Response $-\mathrm{C}_{\mathrm{m}}$ Baseline (Vigh and von Gersdorff, 2005). Statistics were calculated using SigmaPlot (version 11; Systat Software), GraphPad Prism (version 6.01), IgorPro software (version 5.03; Wavemetrics), and Excel (Microsoft). Paired or unpaired Student's $t$ tests were used for comparisons between groups; data are presented as mean \pm SEM, with $p<0.05$ considered a significant difference. For I-V curves and current-clamp ramps, paired Student's $t$ tests were performed on parameters obtained from normalized, leak-
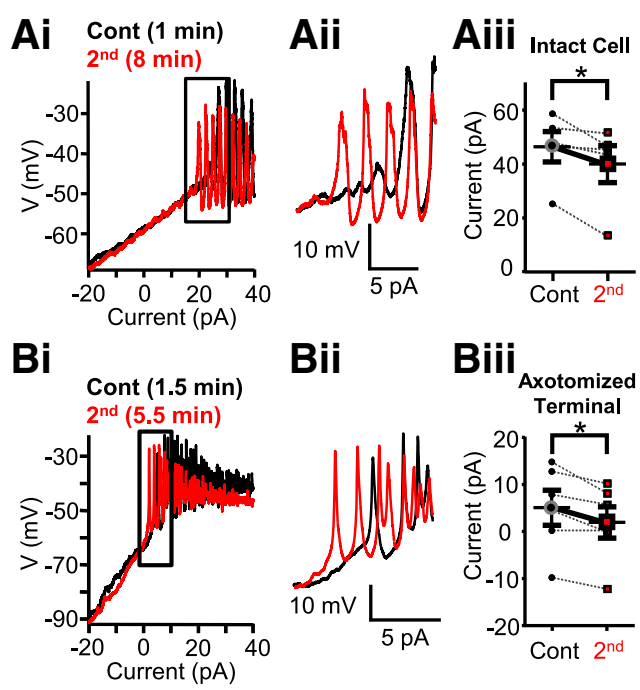

$\mathrm{Bii}$

\section{Biii}
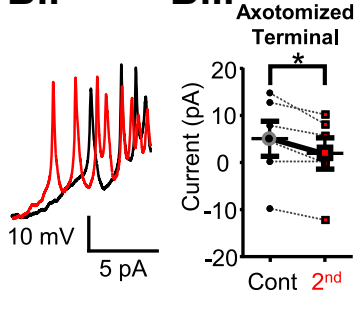

Figure 1. Strong depolarization shifted calcium spike threshold in Mb-type bipolar cells. $A \boldsymbol{i}$ Consecutive current ramp recordings made directly from the large axon terminals of intact Mbs in goldfish retinal slice preparation. Less depolarizing current was needed to evoke spikes when a second current ramp was applied 8 min (red) after the first (black). Aii, Enlargement of $\boldsymbol{A i}$ focusing on the region of spike initiation. The initiation of spikes is shifted leftward for the $8 \mathrm{~min}$ trace. Aiii, Summary showing less current required for the initiation of $\mathrm{Ca}^{2+}$ spikes in terminals of whole Mbs in response to current ramp when preceded by strong depolarization. Data are taken from leak-subtracted and normalized traces. ${ }^{*} p=0.03$ (paired Student's $t$ test). $n=5$ Bi, Current ramp evoked $\mathrm{Ca}^{2+}$ spikes recorded from an axotomized $\mathrm{Mb}$ terminal in slice preparation. The second current ramp (red represents $5.5 \mathrm{~min}$ after break-in) triggered spikes with less depolarizing current than the first current ramp (black represents $1.5 \mathrm{~min}$ after break-in). $\mathbf{B i i}$, Enlargement of the regions of spike initiation from $\mathbf{B i}$. There is a leftward shift in the red trace. Biii, Summary showing that less current is required for the initiation of $\mathrm{Ca}^{2+}$ spikes in axotomized Mb terminals in response to current ramp when preceded by strong depolarization. Data are taken from leak-subtracted and normalized traces. ${ }^{*} p=0.02$ (paired Student's $t$ test). $n=5$. Data are mean \pm SEM.

subtracted pairs of traces unless otherwise noted. For light-evoked spiking responses, paired Student's $t$ tests were performed on latencies determined from original recordings of membrane potentials. One-way ANOVA with Tukey's multiple-comparison test was used for analyzing light-evoked spiking response latencies obtained after sensitizing light stimulations with different intensities.

\section{Results}

Strong depolarization shifted calcium spike threshold in Mb-type bipolar cells

The classical view by which visual signals are coded by slow, graded potentials in BCs (Werblin and Dowling, 1969) has been challenged by observations made in many species: some BCs signal with light-evoked sodium spike in ground squirrel (Saszik and DeVries, 2012) and with calcium $\left(\mathrm{Ca}^{2+}\right)$ spikes in goldfish (Saito et al., 1979), zebrafish (Dreosti et al., 2011; Baden et al., 2011), and mouse (Baden et al., 2013a). However, the role of $\mathrm{Ca}^{2+}$ spike-coded, digital signaling by BCs in visual information processing is not fully understood (for review, see Baden et al., 2013b). Voltage-gated $\mathrm{Ca}^{2+}$ channels, expressed at the axon terminal region, play a critical role in the spiking light responses of Mb-type BCs in the goldfish retina (Zenisek and Matthews, 1998; Protti et al., 2000); therefore, $\mathrm{Ca}^{2+}$ spikes have been proposed to play a role in transmitter release (Zenisek and Matthews, 1998). We made whole-cell current-clamp recordings directly from the large axon terminals of intact Mbs in goldfish retinal slice preparation. With a $\mathrm{K}^{+}$-based internal solution in the recording pipette, a current-ramp protocol from $-20 \mathrm{pA}$ to $65 \mathrm{pA}$ over $2 \mathrm{~s}$ induced membrane potential spikes in Mbs (Fig. 1Ai,Aii). The 
depolarizing current threshold of calcium spike initiation was determined using baseline-subtracted and normalized recordings (for details, see Materials and Methods) from which the current value, in turn, was used to determine the membrane potential threshold on the original traces. We found that, in intact Mbs, the depolarizing current needed to reach the spike threshold was between $25.5 \mathrm{pA}$ and $59.3 \mathrm{pA}$, averaging $46.76 \pm$ $5.76 \mathrm{pA}$, giving the average membrane potential threshold for $\mathrm{Ca}^{2+}$ spikes a value of $-38.66 \pm 5.13 \mathrm{mV}(n=5)$ at the axon terminal. These values fell into the range of $\mathrm{Ca}^{2+}$ spike threshold for BCs in the zebrafish retina (Baden et al., 2011). Interestingly, when we applied a second current-clamp ramp at least $2.5 \mathrm{~min}$ after the completion of the first, we found that less depolarizing current (between $13.1 \mathrm{pA}$ and $51.7 \mathrm{pA}$, averaging $40.24 \pm 6.91$ pA) was necessary to induce a $\mathrm{Ca}^{2+}$ spike (Fig. 1Aii). In other words, the membrane potential threshold for $\mathrm{Ca}^{2+}$ spike initiation was lower during the second current-ramp $(-42.95 \pm 5.92$ $\mathrm{mV}$ ) than that during the first (control). Concurrently, the decrease in membrane potential threshold $(-4.30 \pm 1.46 \mathrm{mV})$ was significant ( $p=0.02$, paired Student's $t$ test). Importantly, the holding current $\left(\mathrm{I}_{\text {hold }}\right)$ needed to keep Mbs at $-60 \mathrm{mV}$ did not change during the recordings ( $\mathrm{I}_{\text {hold }}$ first ramp: $-99.25 \pm 31.16$ pA vs $\mathrm{I}_{\text {hold }}$ second ramp: $-99.75 \pm 32.98 \mathrm{pA}, \Delta \mathrm{I}_{\text {hold }}:-0.5 \pm 1.81$ $\mathrm{pA})$, indicating that the input resistance was unaltered between consecutive ramps.

Next, we tested whether the shift in $\mathrm{Ca}^{2+}$ spike threshold was related to the perfusion, over time, of intact cells with complex morphology. In the next set of experiments, we targeted terminals of Mbs whose axon was severed. In concert with their simple morphology, axotomized $\mathrm{Mb}$ terminals exhibit a single-exponential membrane time constant and have high input resistance (i.e., "less leaky") in the absence of dendritic and somatic inputs (Palmer et al., 2003). The data included for processing were obtained from axotomized $\mathrm{Mb}$ terminals with $\mathrm{I}_{\text {hold }}$ recorded at patch-break between $-3 \mathrm{pA}$ and $-38.5 \mathrm{pA}$, averaging $-24.35 \pm$ $6.16 \mathrm{pA}(n=5)$. Consistent with the high input resistance, the depolarizing current threshold during the first ramp for $\mathrm{Ca}^{2+}$ spike initiation was much lower $(8.06 \pm 2.65 \mathrm{pA})$ than that for intact Mbs. Importantly, during a second ramp, which was delivered with at least 2.5 min delay, $\mathrm{Ca}^{2+}$ spikes were triggered earlier in axotomized $\mathrm{Mb}$ terminals (Fig. $1 \mathrm{Bi}, \mathrm{Bii}$ ) in a similar fashion to that observed in intact Mbs. In other words, a significant reduction in depolarizing current threshold for initiation of $\mathrm{Ca}^{2+}$ spikes was seen $(4.84 \pm 2.07 \mathrm{pA}, p=0.02$, paired Student's $t$ test $)$ (Fig. 1Biii) without a change in $\mathrm{I}_{\text {hold }}(23.7 \pm 6.03 \mathrm{pA})$ compared with that recorded at patch break $\left(\Delta \mathrm{I}_{\text {hold }}: 0.60 \pm 0.15 \mathrm{pA}\right)$. Converting the depolarizing current threshold values into membrane potentials, the data showed that, in axotomized Mb terminals, the initial $\mathrm{Ca}^{2+}$ spike threshold of $-44.81 \pm 2.37 \mathrm{mV}$ measured during the first ramp dropped to $-50.84 \pm 3.33 \mathrm{mV}$ during the second ramp, and this reduction was statistically significant ( $p=$ 0.004 , paired Student's $t$ test). The spike threshold values obtained in axotomized $\mathrm{Mb}$ terminals were lower than those obtained from intact Mbs for both the first and second ramps $(-44.81 \pm 2.37 \mathrm{mV}$ vs $-38.66 \pm 5.13 \mathrm{mV}$, and $-50.84 \pm 3.33$ $\mathrm{mV}$ vs $-42.95 \pm 5.92 \mathrm{mV}$, respectively) demonstrating that depolarizing current injections triggered $\mathrm{Ca}^{2+}$ spikes more efficiently in axotomized $\mathrm{Mb}$ terminals with more compact structure than in intact cells possessing complex morphology. However, when the corresponding spike thresholds were compared (i.e., spike threshold during first ramp in intact cells vs spike threshold during first ramp in axotomized terminals and thresholds during the second ramps in a similar manner), we found no statistical difference between them ( $p=0.3$ and $p=0.2$ for first and second ramp thresholds, respectively, unpaired Student's $t$ test). These results also indicated that the observed reduction of $\mathrm{Ca}^{2+}$ spike threshold was independent of any process in the somatodendritic compartment of Mbs and/or the outer retinal circuitry.

\section{Strong depolarization induced modulation of voltage-gated calcium $\left(\mathrm{I}_{\mathrm{Ca}}\right)$ but not voltage-gated potassium $\left(\mathrm{I}_{\mathrm{K}}\right)$ currents in $\mathrm{Mb}$ terminals}

In the next set of experiments, we tested whether the $\mathrm{Ca}^{2+}$ spike threshold shift we described above might have been caused by changes in the membrane currents mediating $\mathrm{Ca}^{2+}$ spikes. The ionic currents responsible for the spiking response of $\mathrm{Mb}$ terminals consist of rapidly activating (Mennerick and Matthews, $1998)$ voltage-gated influx of $\mathrm{Ca}^{2+}\left(\mathrm{I}_{\mathrm{Ca}}\right)$ through L-type voltagegated $\mathrm{Ca}^{2+}$ channels (Heidelberger and Matthews, 1992; von Gersdorff and Matthews, 1996; Tachibana, 1999) that appear to be $\mathrm{Ca}_{\mathrm{V}} 1.3$ type (Logiudice et al., 2006) and subsequent efflux of $\mathrm{K}^{+}$, made up by voltage-gated $\mathrm{K}^{+}\left(\mathrm{I}_{\mathrm{K}}\right)$ and big conductance $(\mathrm{BK})$ $\mathrm{Ca}^{2+}$-dependent $\mathrm{K}^{+}\left(\mathrm{I}_{\mathrm{K}(\mathrm{Ca})}\right)$ currents (Kaneko and Tachibana, 1985; Sakaba et al., 1997; Palmer, 2006).

To study which one of these ionic currents might be responsible for the shift in spike initiation, we performed whole-cell voltage-clamp recordings on axotomized $\mathrm{Mb}$ terminals using pairs of consecutive voltage-clamp ramp protocols (from -100 $\mathrm{mV}$ to $+50 \mathrm{mV}$, in $2 \mathrm{~s}$ ) at least $3 \mathrm{~min}$ apart. First, we isolated $\mathrm{I}_{\mathrm{K}}$ using a $\mathrm{K}^{+}$-based internal solution (see Materials and Methods) and by complete blockade of $\mathrm{I}_{\mathrm{Ca}}$ with $100 \mu \mathrm{M} \mathrm{CdCl}_{2}$ in the external solution (Fig. 2Ai). Blockers of $\mathrm{I}_{\mathrm{Ca}}$ have been shown to eliminate $\mathrm{I}_{\mathrm{K}(\mathrm{Ca})}$ in Mbs as well (Kaneko and Tachibana, 1985; Palmer, 2006). Figure $2 A i$ shows a representative recording of $I_{K}$ traces evoked by consecutive voltage ramps, applied 3 min apart. Holding potentials $<-60 \mathrm{mV}$ were excluded from the figure for expansion of the physiologically relevant membrane potential region, although the entire current trace was included in the analysis. Analysis was performed on leak-subtracted $\mathrm{I}_{\mathrm{K}}$ recordings fit with a Boltzmann function (see Materials and Methods). Once fit, kinetics of the control ramp I-V and second ramp I-V were reflected by the slope factor $(S)$ of the $I_{K}$ activation and the membrane potential resulting in $50 \%$ activation of $\mathrm{I}_{\mathrm{K}}\left(\mathrm{V}_{(1 / 2)}\right)$ (Griguer and Fuchs, 1996). No significant difference was found in the slope factors of control ramp I-Vs compared with those of the second ramp I-Vs $(0.66 \pm 0.08 \mathrm{mV}$ vs $0.63 \pm 0.09 \mathrm{mV}$, respectively, Fig. 2Aii; paired Student's $t$ test, $p=0.4, n=5$ ) or between $\mathrm{V}_{(1 / 2)}$ values (control: $-11.42 \pm 1.13 \mathrm{mV}$ vs second ramp I-V: $-11.01 \pm 1.66 \mathrm{mV}$; Fig. 2Aiii; paired Student's $t$ test, $p=0.7, n=5$ ).

$\mathrm{I}_{\mathrm{Ca}}$, in axotomized $\mathrm{Mb}$ terminals, was evoked by applying the same linear ramp protocol used for triggering $\mathrm{I}_{\mathrm{K}}$ in voltage-clamp mode, but in the presence of $\mathrm{Cs}^{+}$- based internal solution containing TEA-Cl to block $\mathrm{I}_{\mathrm{K}}$ and $\mathrm{I}_{\mathrm{K}(\mathrm{Ca})}$ (Kaneko and Tachibana, 1985). When kinetics of $\mathrm{I}_{\mathrm{Ca}} \mathrm{I}-\mathrm{V}$ traces recorded under these conditions (Fig. 2Bi) were evaluated by obtaining measurements of the membrane potential relating to $5 \%, 50 \%$, and peak $\mathrm{I}_{\mathrm{Ca}}\left(\mathrm{V}_{(5 \%)}\right.$, $\mathrm{V}_{(50 \%)}$, and $\mathrm{V}_{(\text {Max })}$, respectively; see Materials and methods), we found that, on average, $\mathrm{V}_{(5 \%)}$ was $-40.5 \pm 0.86 \mathrm{mV}, \mathrm{V}_{(50 \%)}$ was $-27.6 \pm 0.80 \mathrm{mV}$, and $\mathrm{V}_{(\mathrm{Max})}$ was $-14.7 \pm 1.00 \mathrm{mV}$ for the $\mathrm{I}_{\mathrm{Ca}}$ $\mathrm{I}-\mathrm{V}$ curves evoked by the first (control) voltage ramp. These values, obtained in slice preparation, were in perfect agreement with earlier reports studying parameters of $\mathrm{I}_{\mathrm{Ca}}$ in dissociated, solitary Mbs (Kaneko and Tachibana, 1985; Heidelberger and Matthews, 1992). However, when we applied an identical second voltageclamp ramp stimulus with at least 2.5 min delay, a portion of the 
resulted $\mathrm{I}_{\mathrm{Ca}}$ did not overlap with that evoked by the first ramp protocol (Fig. $2 B i): \mathrm{I}_{\mathrm{Ca}}$ triggered by the second ramp activated at more negative membrane potentials. On average, for the second ramp, evoked $\mathrm{I}_{\mathrm{Ca}} \mathrm{I}-\mathrm{V} \mathrm{V}_{(5 \%)}$ was $-43.5 \pm 0.79$ $\mathrm{mV}, \mathrm{V}_{(50 \%)}$ was $-30.35 \pm 0.75 \mathrm{mV}$ and $\mathrm{V}_{\text {(Max) }}$ was $-17.2 \pm 0.95 \mathrm{mV}$ (Fig. 2Bii). The difference between the first and second ramp I-V parameters was $-3.0 \pm$ $0.39 \mathrm{mV}$ for $\mathrm{V}_{(5 \%)},-2.75 \pm 0.25 \mathrm{mV}$ for $\mathrm{V}_{(50 \%)}$, and $-2.5 \pm 0.31 \mathrm{mV}$ for $\mathrm{V}_{(\mathrm{Max})}$, all proven to be statistically significant $\left(\mathrm{V}_{(5 \%)}: p=0.00003 ; \mathrm{V}_{(50 \%)}: p=0.000001\right.$; $\mathrm{V}_{(\text {Max })}: p=0.00001$; paired Student's $t$ test, $n=10$ ) (Fig. 2Bii). It is important to note that, once shifted, we found that (1) subsequent ramp I-Vs were insufficient to shift $\mathrm{I}_{\mathrm{Ca}}$ activation kinetics further to the left and (2) shifted $\mathrm{I}_{\mathrm{Ca}} \mathrm{I}$-Vs did not return to their initial control values within the timeframe of a recording (up to $20 \mathrm{~min}$ ), set by $>10 \%$ rundown of peak $\mathrm{I}_{\mathrm{Ca}}$ (data not shown).

$\mathrm{I}_{\mathrm{Ca}} \mathrm{I}-\mathrm{V}$ traces evoked by consecutive depolarizing voltage ramps were also analyzed by comparing the parameters of their modified Boltzmann function fits (Leuranguer et al., 2003). We found a difference in halfactivation $\left(\mathrm{V}_{(1 / 2) \text { first }}:-26.34 \pm 0.80 \mathrm{mV}\right.$ vs $\mathrm{V}_{(1 / 2) \text { second: }}-29.24 \pm 0.84 \mathrm{mV}$; Figure 2Biii) and in the peak $\mathrm{I}_{\mathrm{Ca}}\left(\mathrm{V}_{\text {Peaklst }}\right.$ : $-16.03 \pm 0.95 \mathrm{mV}$ vs $\mathrm{V}_{\text {Peak2nd }}$ : $-18.55 \pm$ $1.0 \mathrm{mV}$; Fig. 2Biv); the differences in both parameters were statistically significant $\left(\mathrm{V}_{(1 / 2)}: p=0.000002 ; \mathrm{V}_{\text {Peak }}: p=0.00004\right.$; paired Student's $t$ test, $n=10$ ). These results were entirely consistent with the results of analysis based on I-V characteristics obtained directly from the I-V curves. Although the half-activation $\left(\mathrm{V}_{(50 \%)}\right.$ vs $\left.\mathrm{V}_{(1 / 2)}\right)$ and peak $\mathrm{I}_{\mathrm{Ca}}$ membrane potential $\left(\mathrm{V}_{(\text {Max })}\right.$ vs $\left.\mathrm{V}_{\text {Peak }}\right)$ values for the same $\mathrm{I}_{\mathrm{Ca}} \mathrm{I}-\mathrm{V}$ curves obtained by the two methods were not identical, the differences between the corresponding values were not statistically significant $\left(\mathrm{V}_{(50 \%)}\right.$ vs $\mathrm{V}_{(1 / 2)}$ first: $p=0.14$, second: $p=0.16$; $\mathrm{V}_{\text {(Max) }}$ vs $\mathrm{V}_{\text {Peak }}$ first: $p=0.35$, second: $p=$ 0.34 ; paired Student's $t$ test, $n=10$ ). There was no significant difference in the reversal potential $\left(\mathrm{V}_{\text {rev }}\right)$ of $\mathrm{I}_{\mathrm{Ca}}$ between the first (control) and second ramp I-Vs $\left(\mathrm{V}_{\text {revlst }}: 37.70 \pm\right.$ $1.84 \mathrm{mV}$ vs $\mathrm{V}_{\text {rev2nd }}: 36.65 \pm 1.78 \mathrm{mV} ; p=$ 0.31 ; paired Student's $t$ test, $n=10$; Fig. $2 B v$ ), which supported the view that the leftward shift in $\mathrm{I}_{\mathrm{Ca}}$ activation did not originate from an artifact caused by a drift in electrode potential over the course of our experiments. Although the average slope factor $\left(\mathrm{k}_{\mathrm{G}}\right)$ slightly increased between the corresponding first (control) and second $\mathrm{I}_{\mathrm{Ca}} \mathrm{I}-\mathrm{Vs}_{\mathrm{s}}\left(\mathrm{k}_{\mathrm{G} 1 \mathrm{st}}\right.$ : $4.18 \pm 0.23 \mathrm{mV}$ vs $\mathrm{k}_{\mathrm{G} 2 n d}: 4.44 \pm 0.23 \mathrm{mV}$ ), this increase was not statistically significant ( $p=0.052$, paired Student's $t$ test, $n=10$ ).
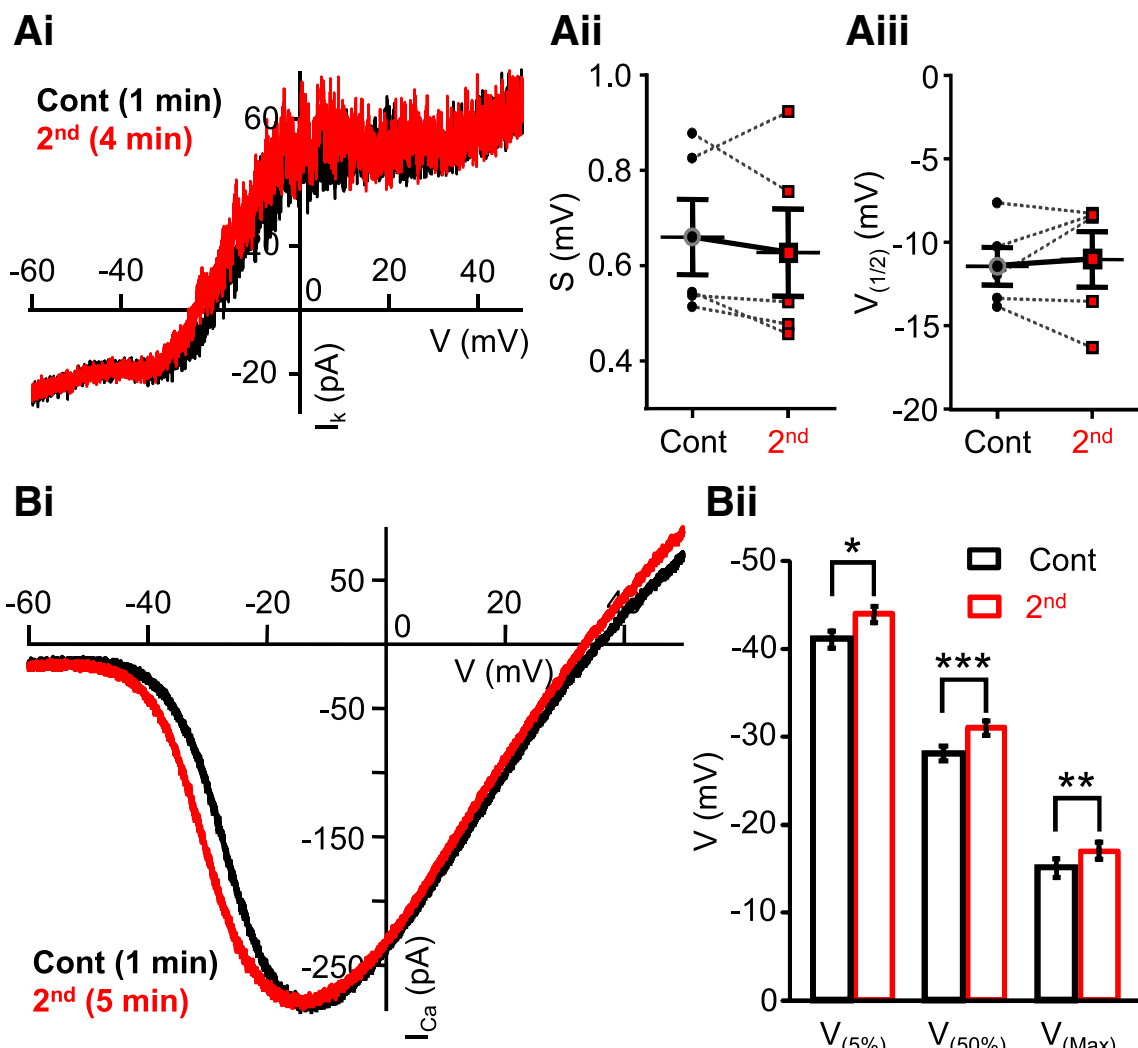

$\mathrm{Bii}$
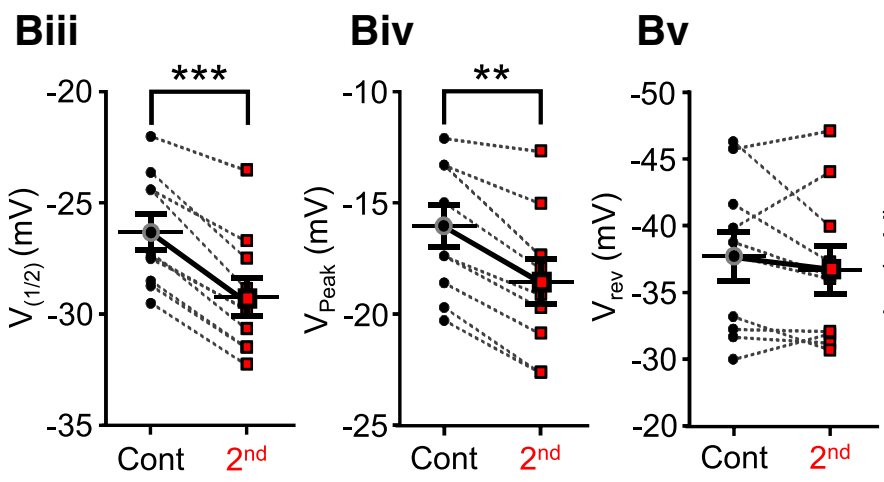

Bvi

Figure 2. Strong depolarization induced modulation of $\mathrm{I}_{\mathrm{Ca}}$ activation but not $\mathrm{I}_{\mathrm{K}}$ kinetics. Ai, Potassium current $\left(\mathrm{I}_{\mathrm{K}}\right)$ in axotomized $\mathrm{Mb}$ terminal in response evoked by a voltage ramp from $-100 \mathrm{mV}$ to $50 \mathrm{mV}$ for $2 \mathrm{~s}$. Points below $-60 \mathrm{mV}$ have been removed for illustration purposes. Black trace represents $1 \mathrm{~min}$ after break-in; red trace represents 4 min after break-in. $\mathrm{I}_{\mathrm{K}}$ was isolated by blocking $\mathrm{I}_{\mathrm{Ca}}$ with $100 \mu \mathrm{M}$ $\mathrm{CdCl}_{2}$. The second trace (red) coincides with the control (black). Aii, No significant differences were observed between the slope factor (S) of control and second traces. Black circles represent control; red squares represent second. $n=5$. Aiiii, The membrane potential at $50 \%$ of the maximal current $\left(\mathrm{V}_{(50 \%)}\right)$ did not differ in the first and second recordings. Black circles represent control; red squares represent second. $n=$ 6. Bi, Consecutive $\mathrm{I}_{\mathrm{Ca}} \mathrm{I}-\mathrm{Vs}$ generated from an axotomized terminal in slice preparation, in response to a $2 \mathrm{~s}$ voltage ramp. There is a shift in the trace recorded at 5 min after break-in (red) compared with the control trace recorded 1.5 min after break-in (black). Bii, Summary graph showing $\mathrm{I}_{\mathrm{Ca}}$ activation $\left(\mathrm{V}_{(5 \%)}\right)$, half-activation $\left(\mathrm{V}_{(50 \%)}\right)$, and peak $\left(\mathrm{V}_{(\mathrm{Max}}\right)$. Black represents control; red represents second. ${ }^{*} p=0.00003$ (paired Student's ttest). ${ }^{* * *} p=0.000001$ (paired Student's ttest). ${ }^{* *} p=0.00001$ (paired Student's ttest). $n=10$. Biii, Summary graph showing half-activation $\left(V_{1 / 2}\right)$ parameter from Boltzmann fits is significantly less for the second voltage-ramps compared with control. Black circles represent control; red squares represent second. ${ }^{* *} p=0.000002$ (paired Student's $t$ test). $n=10$. Biv, Summary graph showing significant shift in peak parameter obtained from Boltzmann fits. Black circles represent control; red squares represent second. ${ }^{* *} p=0.00004$ (paired Student's $t$ test). $n=10 . B v$, Summary graph of pairwise comparisons displaying no difference in the reversal potential $\left(V_{\text {rev }}\right)$ parameter obtained from Boltzmann fits. Black circles represent control; red squares represent second. $p=0.31$ (paired Student's $t$ test). $n=10$. Bvi, Summary graph showing no significant difference in the slope factor $\left(k_{\mathrm{G}}\right)$ parameter obtained from Boltzmann fits for control and second voltage ramps. Black circles represent control; red squares represent second. $p=0.052$ (paired Student's $t$ test). $n=10$. Data are mean \pm SEM.

This was consistent with the fact that the slope increased in only 6 of 10 recordings, whereas in the rest of the cases it decreased ( 4 of 10) or remained the same ( 1 of 10; Fig. 2Bvi). These results suggested that a change in voltage dependence of $\mathrm{Ca}^{2+}$ channel gating charges (Hille, 
2001) was not a critical mediator of the leftward shift observed in $\mathrm{I}_{\mathrm{Ca}}$ activation.

The threshold values for $\mathrm{Ca}^{2+}$ spikes in axotomized $\mathrm{Mb}$ terminals measured with current ramps and $\mathrm{I}_{\mathrm{Ca}}$ activation $\left(\mathrm{V}_{(5 \%)}\right)$ measured with voltage-clamp ramps were in great agreement, suggesting that the leftward shift in $\mathrm{I}_{\mathrm{Ca}}$ activation threshold was responsible for the reduction in $\mathrm{Ca}^{2+}$ spike threshold.

Although it was not tested, we considered direct contribution of $(\mathrm{BK}) \mathrm{I}_{\mathrm{K}(\mathrm{Ca})}$ to the shift of $\mathrm{Ca}^{2+}$ spike threshold to be highly unlikely: to open $(\mathrm{BK}) \mathrm{I}_{\mathrm{K}(\mathrm{Ca})}$ channels require large membrane depolarization (Vergara et al., 1998; Sah and Davies, 2000) and $10-20 \mu \mathrm{M}\left[\mathrm{Ca}^{2+}\right]_{\mathrm{i}}$ in $\mathrm{Mb}$ terminals (Sakaba et al., 1997). Thus, (BK) $\mathrm{I}_{\mathrm{K}(\mathrm{Ca})}$ channels are not active at membrane potentials below $\mathrm{I}_{\mathrm{Ca}}$ activation.

The depolarization induced shift in $\mathrm{I}_{\mathrm{Ca}}$ activation at $\mathrm{Mb}$ terminals was calcium-dependent and required glutamatemediated synaptic signaling

Subjecting Mb terminals to 2-s-long depolarizing ramp protocols in retinal slice preparation changed the activation kinetics of $\mathrm{I}_{\mathrm{Ca}}$. To explore whether this change was related to the massive influx of $\mathrm{Ca}^{2+}$ triggered by these protocols, we generated consecutive $\mathrm{I}-\mathrm{V}$ curves for $\mathrm{I}_{\mathrm{Ca}}$ at least $2.5 \mathrm{~min}$ apart in a stepwise manner using 3 -ms-long square pulse voltage steps between -80 and $60 \mathrm{mV}$ (see Materials and Methods). This stepwise protocol dramatically reduced the total $\mathrm{Ca}^{2+}$ influx at the $\mathrm{Mb}$ terminal over the course of experiment: between -80 and $40 \mathrm{mV}$, the cumulative step induced $\mathrm{Ca}^{2+}$ charge transfer $(\mathrm{Q})$ was only $\sim 0.02 \%$ of that triggered by a $2 \mathrm{~s}$ ramp (data not shown). In addition, the delay between consecutive short depolarizing steps presumably allowed mobile and fixed $\mathrm{Ca}^{2+}$ buffering systems of the Mb terminals (Burrone et al., 2002) to control the spatial and temporal parameters of intracellular $\mathrm{Ca}^{2+}$ microdomains (Neher, 1998), formed during each short depolarizing step, at higher efficacy than during a long ramp depolarization. It is important to emphasize that, in our whole-cell recordings, the standard internal solutions contained 2 mM EGTA (see Materials and Methods), which slightly overestimated the $\mathrm{Ca}^{2+}$ buffering capacity of mobile endogenous buffers of Mb terminals (Burrone et al., 2002).

Analysis of parameters obtained from a modified Boltzmann function fit of the data points was used to determine potential differences between the characteristics of consecutive stepwise I-V curves (Fig. $3 A$ ). On average, the slope factor $\left(\mathrm{k}_{\mathrm{G}}\right)$ was $5.27 \pm$ $0.29 \mathrm{mV}$ for first (control) and $5.27 \pm 0.31 \mathrm{mV}$ for the second stepwise $\mathrm{I}-\mathrm{V}, \mathrm{V}_{(1 / 2)}$ was $-27.80 \pm 1.00 \mathrm{mV}$ for first (control) and $-28.36 \pm 0.95 \mathrm{mV}$ for the second stepwise $\mathrm{I}-\mathrm{V}$, and $\mathrm{V}_{\text {Peak }}$ was $-12.27 \pm 0.93 \mathrm{mV}$ for control and $-12.87 \pm 1.11 \mathrm{mV}$ for the second stepwise I-V. No significant difference between the parameters of control and second stepwise $\mathrm{I}-\mathrm{V}$ was found $\left(\mathrm{k}_{\mathrm{G}}: p=\right.$ $0.96 ; \mathrm{V}_{(1 / 2)}: p=0.27$ and $\mathrm{V}_{\text {Peak }}: p=0.11$, paired Student's $t$ test, $n=13)$. The lack of change in $\mathrm{I}_{\mathrm{Ca}}$ activation kinetics under these conditions indicated that the negative shift in $\mathrm{I}_{\mathrm{Ca}}$ activation observed in Mbs in experiments using consecutive depolarizing linear ramp protocols was dependent upon (large) $\mathrm{Ca}^{2+}$ influxmediated intracellular processes, specifically, those processes that could be triggered by ramp protocols but not by short depolarizing steps.

Supporting this notion, when the pipette solution was supplemented with $10 \mathrm{~mm}$ BAPTA in place of the regularly used $2 \mathrm{~mm}$ EGTA, $\mathrm{I}_{\mathrm{Ca}} \mathrm{I}-\mathrm{Vs}$ generated by consecutive voltage-clamp ramp protocols ( $-100 \mathrm{mV}$ to $50 \mathrm{mV}$, over $2 \mathrm{~s}$, at least $2.5 \mathrm{~min}$ apart) overlapped (Fig. $3 B$ ). On average, $\mathrm{V}_{(5 \%)}$ was $-39.0 \pm 1.75 \mathrm{mV}$ for control and $-39.30 \pm 1.95 \mathrm{mV}$ for the second ramp $\mathrm{I}-\mathrm{V}, \mathrm{V}_{(50 \%)}$
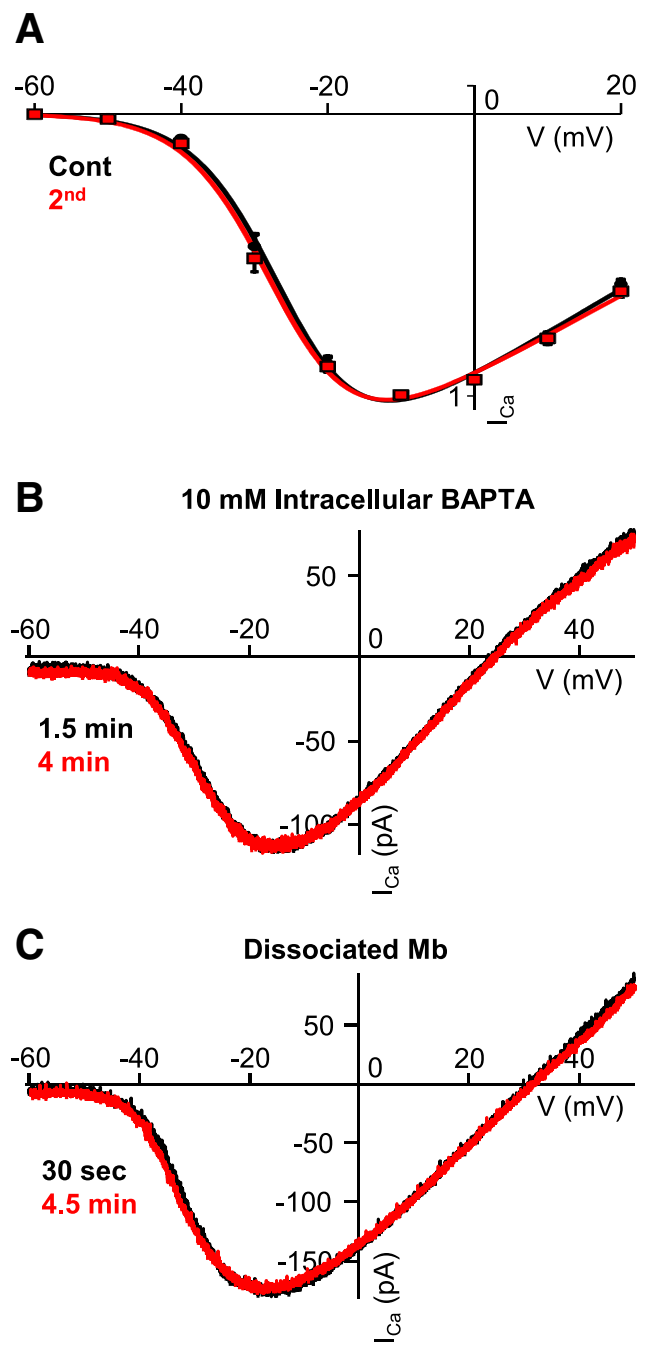

Figure 3. Modulation of $\mathrm{I}_{\mathrm{Ca}}$ at the $\mathrm{Mb}$ terminal is $\mathrm{Ca}^{2+}$-dependent and required synaptic signaling. $\boldsymbol{A}$, Average (leak-subtracted and normalized) stepwise I-V curve from axotomized terminals in slice preparation ( $n=13$ for steps to $\leq-10 \mathrm{mV}, n=9$ for steps to $0 \mathrm{mV}$ and 20 $\mathrm{mV}$ ). Consecutive I-V curves were generated $3 \mathrm{~min}$ apart by using $3 \mathrm{~ms}$ voltage steps. Data were fitted with a modified Boltzmann equation, smooth line (black represents first, control I-V; red represents second I-V). Data are mean \pm SEM. $B$, Chelation of ramp-evoked $C^{2}{ }^{2+}$ influx using BAPTA (10 mm) inhibited strong depolarization-induced modulation of $\mathrm{I}_{\mathrm{Ca}}$ kinetics of axoto-

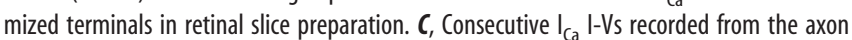
terminal of an enzymatically dissociated, solitary $\mathrm{Mb}$. The voltage ramp protocol was the same used in slice preparation. No shift was observed between the control (black) and the second (red) $\mathrm{I}_{\mathrm{Ca}} \mathrm{I}-\mathrm{V}$.

was $-23.95 \pm 1.09 \mathrm{mV}$ for control and $-23.71 \pm 2.11 \mathrm{mV}$ for the second ramp I-V, and $\mathrm{V}_{(\text {Max })}$ was $-12.59 \pm 1.17 \mathrm{mV}$ for control and $-12.18 \pm 2.22 \mathrm{mV}$ for the second ramp I-V. Statistical analysis revealed that there was no difference between control and second ramp I-V for $\mathrm{V}_{(5 \%)}, \mathrm{V}_{(50 \%)}$, and $\mathrm{V}_{(\text {Max })}(p=0.8, p=0.9$, and $p=0.8$, respectively, paired Student's $t$ test; $n=5)$. Together, these results suggested that modulation of $\mathrm{I}_{\mathrm{Ca}}$ kinetics at the $\mathrm{Mb}$ axon terminal required a strong depolarization, resulting in a large influx of $\mathrm{Ca}^{2+}$, which initiated a $\mathrm{Ca}^{2+}$-dependent presynaptic process that ultimately led to modulation of $\mathrm{I}_{\mathrm{Ca}}$ activation kinetics.

To test whether the $\mathrm{I}_{\mathrm{Ca}}$ activation shift was indeed solely mediated by intracellular process triggered by the enormous $\mathrm{Ca}^{2+}$ influx during long ramp depolarizations, $\mathrm{I}_{\mathrm{Ca}} \mathrm{I}-\mathrm{V}$ s were generated by applying the previously used voltage-clamp ramp protocols 
A

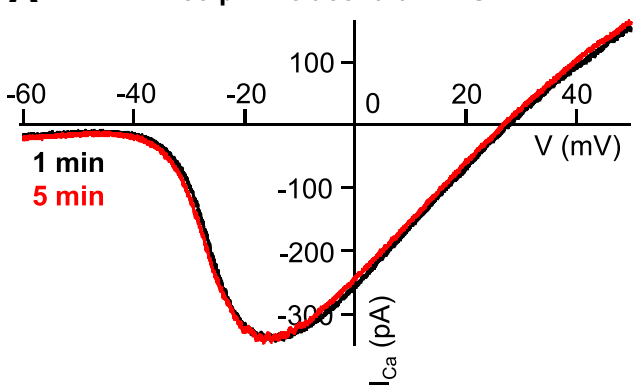

B

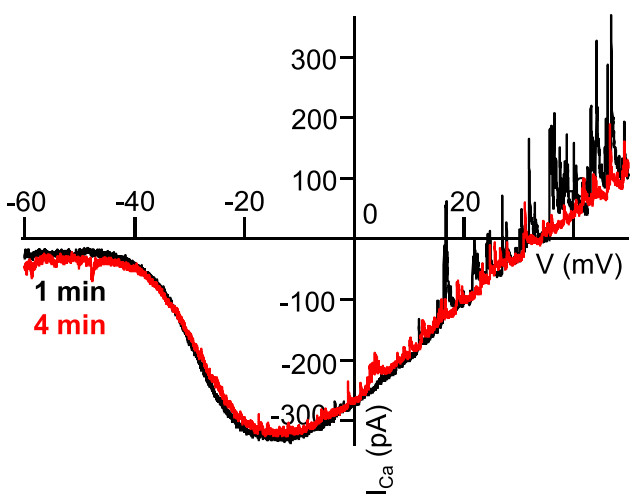

Figure 4. Exocytosis of glutamate and activation of neurons postsynaptic to the Mb terminal are required for modulation of $\mathrm{I}_{\mathrm{Ca}}$. $\boldsymbol{A}$, Consecutive $\mathrm{I}_{\mathrm{Ca}}$ traces recorded from an axotomized $\mathrm{Mb}$ terminal in slice preparation in response to voltage ramps $4 \mathrm{~min}$ apart in the presence of intracellular Ex01 (50 $\mu \mathrm{m})$. The exocytosis inhibitor Ex01 prevented the leftward shift of the second ramp I-V (red) compared with the control ramp I-V (black). $\boldsymbol{B}$, Consecutive $\mathrm{I}_{\mathrm{Ca}}$ traces recorded from an axotomized $\mathrm{Mb}$ terminal in slice preparation, in response to voltage ramps $3 \mathrm{~min}$ apart in the presence of iGluR antagonists NBQX (25 $\mu \mathrm{m})$ and D-AP5 (50 $\mu \mathrm{m})$. The antagonists prevented the leftward shift of the second trace (red) from control (black). There are spontaneous outward GABAergic IPSCs at depolarized potentials in the absence of PTX.

$(-100 \mathrm{mV}$ to $50 \mathrm{mV}$, over $2 \mathrm{~s}$, at least $2.5 \mathrm{~min}$ apart) to the axon terminals of enzymatically dissociated, solitary Mbs using our standard pipette solution containing 2 mM EGTA. We observed no shift in the I-V curves resulted by consecutive ramps (Fig. $3 C$ ): we found $\mathrm{V}_{(5 \%)}$ of $-37.7 \pm 2.04 \mathrm{mV}$ for control and $-37.14 \pm$ $2.26 \mathrm{mV}$ for the second ramp $\mathrm{I}-\mathrm{V}, \mathrm{V}_{(50 \%)}$ of $-21.93 \pm 1.84 \mathrm{mV}$ for control and $-22.71 \pm 1.95 \mathrm{mV}$ for the second ramp I-V, and $\mathrm{V}_{(\text {Max }}$ of $-6.14 \pm 1.75 \mathrm{mV}$ for control and $-8.29 \pm 1.78 \mathrm{mV}$ for the second ramp I-V, with no significant difference between control and second ramp I-Vs for $\mathrm{V}_{(5 \%)}, \mathrm{V}_{(50 \%)}$, and $\mathrm{V}_{(\text {Max })}(p=0.6$, $p=0.4$, and $p=0.4$, respectively, paired Student's $t$ test; $n=7)$. This was in concert with the fact that previous studies of $\mathrm{I}_{\mathrm{Ca}}$ of cultured solitary Mbs using voltage ramps did not report apparent changes in the $\mathrm{I}_{\mathrm{Ca}}$ activation (Kaneko and Tachibana, 1985; Heidelberger and Matthews, 1992). Together, these results suggested that the pathway that mediated large $\mathrm{Ca}^{2+}$ influx-evoked modulation of $\mathrm{I}_{\mathrm{Ca}}$ kinetics at $\mathrm{Mb}$ terminals is likely to have synaptic components driven by the glutamate released from $\mathrm{Mb}$ terminals.

To investigate the role of glutamate release from the Mb terminal in $\mathrm{I}_{\mathrm{Ca}}$ modulation further, we inhibited exocytosis pharmacologically by adding $50 \mu \mathrm{M}$ Exol (Feng et al., 2003) to the internal solution of the recording pipette. In the presence of Exo1 $(50 \mu \mathrm{M})$, the control and second whole-cell voltage-clamp ramp generated $\mathrm{I}_{\mathrm{Ca}}$ I-Vs overlapped (Fig. 4A). With depolarizing voltage ramps in the presence $50 \mu \mathrm{M}$ Exol, for $\mathrm{I}_{\mathrm{Ca}}$ we recorded an average $\mathrm{V}_{(5 \%)}$ of $-41.3 \pm 1.56 \mathrm{mV}$ for control and $-40.94 \pm 1.70$ $\mathrm{mV}$ for the second ramp $\mathrm{I}-\mathrm{V}, \mathrm{V}_{(50 \%)}$ of $-28.73 \pm 1.30 \mathrm{mV}$ for control and $-28.10 \pm 1.36 \mathrm{mV}$ for the second ramp $\mathrm{I}-\mathrm{V}$, and $\mathrm{V}_{(\text {Max }}$ of $-16.68 \pm 1.40 \mathrm{mV}$ for control and $-16.57 \pm 1.33 \mathrm{mV}$ for the second ramp I-V. Statistical analysis revealed no difference between control and second ramp I-Vs $\left(\mathrm{V}_{(5 \%)}: p=0.4\right.$; $\mathrm{V}_{(50 \%)}: p=0.4$; and $\mathrm{V}_{(\mathrm{Max})}: p=0.9$, paired Student's $t$ test; $n=$ 10). The lack of leftward shift of $\mathrm{I}_{\mathrm{Ca}}$ activation was consistent with the notion that inhibiting the ramp-evoked glutamate release from $\mathrm{Mb}$ terminals prevented the activation of processes responsible for the $\mathrm{I}_{\mathrm{Ca}}$ modulation. We could not obtain direct evidence for the reduction of glutamate release in these experiments as membrane capacitance measurements triggered by our standard $2 \mathrm{~s}$ voltage-clamp ramp were unreliable because of the slowly decaying tail currents (Gillis, 2000) that often lasted for $>10 \mathrm{~s}$ after the ramps. Nonetheless, in our hands, intracellular perfusion of axotomized $\mathrm{Mb}$ terminals with Exol $(50 \mu \mathrm{M})$ for at least 4 $\mathrm{min}$ in slice preparation reduced the control membrane capacitance increase in response to $250 \mathrm{~ms}$ depolarizing steps from -60 to $-30 \mathrm{mV}$ by $57.89 \pm 10.09 \%(n=11)$ without altering the depolarization-evoked $\mathrm{I}_{\mathrm{Ca}}$ charge transfer $(103.10 \pm 12.80 \%$, data not shown).

These results collectively suggested that inhibition of glutamate release from $\mathrm{Mb}$ terminals by Exo 1 prevented the large depolarization-evoked modulation of their own $\mathrm{I}_{\mathrm{Ca}}$. This notion was also supported by two sets of results presented earlier showing lack of $\mathrm{I}_{\mathrm{Ca}}$ modulation (1) when $\mathrm{I}_{\mathrm{Ca}}$ I-Vs were generated by a series of short, stepwise depolarizations in an attempt to reduce $\mathrm{Ca}^{2+}$ influx into $\mathrm{Mb}$ terminals, but that protocol coincidentally also reduced overall glutamate release; and (2) in the presence of $10 \mathrm{~mm}$ intracellular BAPTA that was used to prevent $\mathrm{Ca}^{2+}$ triggered intracellular processes; BAPTA at this concentration was shown to effectively eliminate depolarization evoked exocytosis of glutamate from BC terminals (Singer and Diamond, 2003) including Mbs (Vigh and von Gersdorff, 2005).

Addition of the selective AMPA/kainate receptor antagonist NBQX $(25 \mu \mathrm{M})$ and NMDA receptor antagonist D-AP5 $(50 \mu \mathrm{M})$ to the external solution also prevented the characteristic leftward shift in $\mathrm{I}_{\mathrm{Ca}}$ kinetics seen in response to the second voltage-clamp ramp (Fig. 4B). In these experiments, PTX was not present in the recording medium. Thus, spontaneous IPSCs, triggered by GABA release from amacrine cells (ACs), are superimposed on the $\mathrm{I}_{\mathrm{Ca}} \mathrm{I}-\mathrm{V}$ although the reciprocal GABAergic feedback IPSCs, triggered by the depolarization-evoked glutamate release from $\mathrm{Mb}$ terminals, was blocked by ionotropic glutamate receptor (iGluR) antagonists NBQX and D-AP5 (Vigh et al., 2005). In the presence of NBQX $(25 \mu \mathrm{M})$, an D-AP5 $(50 \mu \mathrm{M})$ we found $\mathrm{V}_{(5 \%)}$ of $-40.64 \pm 0.67 \mathrm{mV}$ for control and $-40.53 \pm 0.96 \mathrm{mV}$ for the second ramp $\mathrm{I}-\mathrm{V}, \mathrm{V}_{(50 \%)}$ of $-27.05 \pm 0.49 \mathrm{mV}$ for control and $-27.09 \pm 0.75 \mathrm{mV}$ for the second ramp $\mathrm{I}-\mathrm{V}$, and $\mathrm{V}_{\text {(Max) }}$ of $-13.46 \pm 0.76 \mathrm{mV}$ for control and $-13.66 \pm 0.65 \mathrm{mV}$ for the second ramp I-V. Statistical analysis indicated no significant difference between control and second ramp I-V $\left(\mathrm{V}_{(5 \%)}: p=0.5\right.$; $\mathrm{V}_{(50 \%)}: p=0.9 ; \mathrm{V}_{(\text {Max })}: p=0.4$; paired Student's $t$ test; $\left.n=9\right)$.

As these recordings were obtained exclusively from axotomized $\mathrm{Mb}$ terminals that do not express either presynaptic AMPA/kainate- or NMDA receptors, the site of action of iGluR antagonists by which they prevented a shift in $\mathrm{I}_{\mathrm{Ca}} \mathrm{I}-\mathrm{V}$ can be attributed to neurons postsynaptic to the Mb terminals. Together, these data suggested that modulation of $\mathrm{I}_{\mathrm{Ca}}$ kinetics at the $\mathrm{Mb}$ terminal required large depolarization of $\mathrm{Mb}$ terminals, followed by exocytosis of a large amount of glutamate to activate 


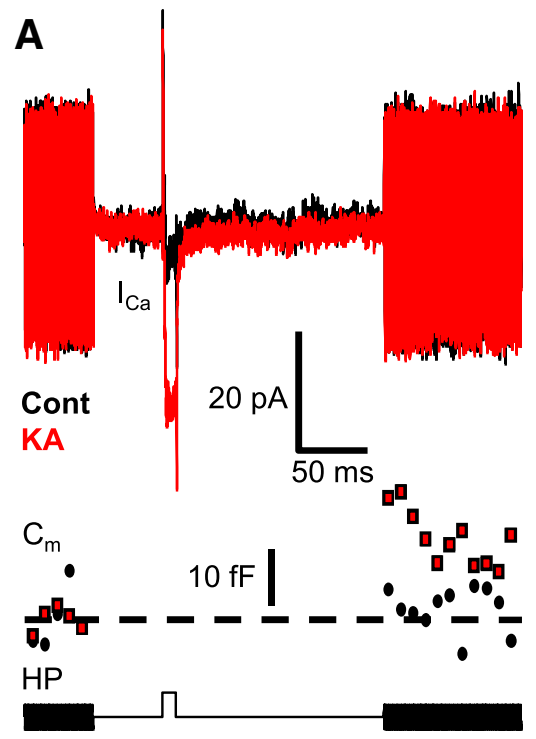

B

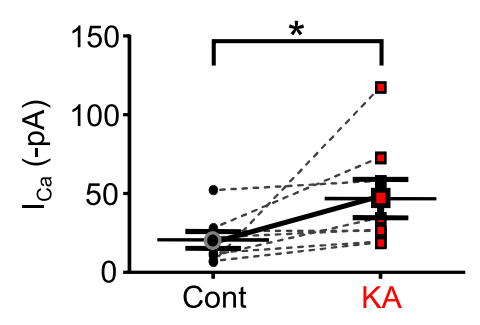

C

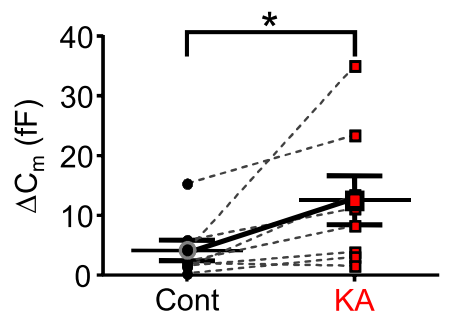

Figure 5. Activation of postsynaptic neurons potentiated $\mathrm{I}_{\mathrm{Ca}}$ and exocytosis from $\mathrm{Mb}$ terminals. $\boldsymbol{A}$, Depolarization of an axotomized $\mathrm{Mb}$ terminal from the holding potential (HP) of -60 to $-40 \mathrm{mV}$ for $10 \mathrm{~ms}$ activated tiny calcium influx through voltagegated calcium channels $\left(\mathrm{I}_{\mathrm{Ca}_{\mathrm{a}}}\right)$, which triggered no glutamate release, as evidenced by the absence of increase in $\mathrm{C}_{\mathrm{m}}$. The protocol used is shown in the bottom trace. The fast voltage sine wave used to measure $C_{m}$ was not delivered during the depolarization. Bath application of $10 \mu \mathrm{M} \mathrm{KA}$ facilitated $\mathrm{I}_{\mathrm{C}_{\mathrm{a}}}$ and enhanced exocytosis $\left(\mathrm{C}_{\mathrm{m}}\right)$ from the axotomized $\mathrm{Mb}$ terminals in response to a depolarizing step from $-60 \mathrm{mV}$ to $-40 \mathrm{mV}$. Black represents control; red represents KA treatment. $\boldsymbol{B}$, Summary figure displaying KA (10 $\mu \mathrm{m}$ ) effect on peak $\mathrm{I}_{\mathrm{Ca}}$ in response to $10 \mathrm{~ms}$ step from $-60 \mathrm{mV}$ to $-40 \mathrm{mV}$. Black circles represent control; red squares represent KA. ${ }^{*} p=0.04$ (paired Student's $t$ test). $n=8$. C, Summary figure displaying KA (10 $\mu \mathrm{m}$ ) effect on $\Delta C_{\mathrm{m}}$ in response to $10 \mathrm{~ms}$ step from $-60 \mathrm{mV}$ to $-40 \mathrm{mV}$. Black circles represent control; red squares represent KA. ${ }^{*} p=0.02$ (paired Student's $t$ test). $n=8$. Data are mean \pm SEM.

postsynaptic neurons, thereby initiating a feedback signal that positively modulated $\mathrm{I}_{\mathrm{Ca}}$ in $\mathrm{Mb}$ terminals.

We tested further whether iGluR activation can trigger modulation of $\mathrm{I}_{\mathrm{Ca}}$ in axotomized $\mathrm{Mb}$ terminals. Specifically, we recorded $\mathrm{I}_{\mathrm{Ca}}$ from axotomized $\mathrm{Mb}$ terminals in response to a $10 \mathrm{~ms}$ depolarizing step from the holding potential of $-60 \mathrm{mV}$ to -40 $\mathrm{mV}$, the membrane potential associated with threshold of L-type $\mathrm{I}_{\mathrm{Ca}}$ in Mbs (Tachibana, 1999) (see also control $\mathrm{V}_{(5 \%)}$; Fig. 2Bi,Bii). As expected, upon depolarization, a tiny inward $\mathrm{I}_{\mathrm{Ca}}$ was seen (Fig. $5 \mathrm{~A}$, black $\mathrm{I}_{\mathrm{Ca}}$ trace), which was associated with a barely detectable (if any) increase in the membrane capacitance $(4.09 \pm 1.72 \mathrm{fF}$, $n=8$ ) of the $\mathrm{Mb}$ terminals (Fig. $5 \mathrm{~A}$, black $\mathrm{C}_{\mathrm{m}}$ trace), indicating negligible glutamate release at this membrane potential (Tachibana, 1999). We then mimicked a large glutamate release from the Mb terminal by superfusing the retinal slices with the iGluR agonist $\mathrm{KA}(10 \mu \mathrm{M})$ for $3 \mathrm{~min}$. The repeated $10 \mathrm{~ms}$ depolarizing step to $-40 \mathrm{mV}$ after $\mathrm{KA}$ application triggered a substantially larger $\mathrm{I}_{\mathrm{Ca}}$ (Fig. $5 A$, red $\mathrm{I}_{\mathrm{Ca}}$ trace): the peak $\mathrm{I}_{\mathrm{Ca}}$ increased from an average value of $-20.66 \pm 5.38 \mathrm{pA}$ under control conditions to $-46.95 \pm 12.19 \mathrm{pA}$ after KA application (Fig. $5 B$ ), which was statistically significant ( $p=0.04$, paired Student's $t$ test; $n=8$ ). Importantly, the elevated $\mathrm{I}_{\mathrm{Ca}}$ triggered a clear increase in the membrane capacitance (Fig. $5 \mathrm{~A}$, red $\mathrm{C}_{\mathrm{m}}$ trace) indicating glutamate release. For the tested $\mathrm{Mb}$ terminals, $\Delta \mathrm{C}_{\mathrm{m}}$ after $\mathrm{KA}$ increased to $12.49 \pm 4.08 \mathrm{fF}$ ( $p=0.02$, paired Student's $t$ test; $n=$ 8; Fig. $5 A, C)$.

KA did not trigger any membrane currents in axotomized $\mathrm{Mb}$ terminals in the presence of PTX; therefore, these results suggested that KA depolarized neurons postsynaptic to the Mb terminal and initiated a feedback pathway. The increase in the depolarizing step evoked $\mathrm{I}_{\mathrm{Ca}}$, associated with a significant increase in the glutamate release from $\mathrm{Mb}$ terminals at a physiolog- ically relevant membrane potential in the presence of KA was consistent with the notion that KA might have triggered some endogenous feedback signal generation in the inner retina, which then shifted $\mathrm{I}_{\mathrm{Ca}}$ activation to more negative potentials.

\section{NO as a retrograde messenger- modulated $\mathrm{I}_{\mathrm{Ca}}$ at $\mathrm{Mb}$ terminals} Our data presented so far implicated the presence of a retrograde signal that plays a critical role in (strong) stimulation evoked modulation of $\mathrm{I}_{\mathrm{Ca}}$ at $\mathrm{Mb}$ axon terminals. A prime candidate for such a retrograde signaling molecule is $\mathrm{NO}$ as it has been shown to shift $\mathrm{I}_{\mathrm{Ca}}$ activation to more negative potentials in both rod photoreceptors (Kurenny et al., 1994) and cultured GCs (Hirooka et al., 2000) and is known to be released from inner retinal neurons by light (Eldred and Blute, 2005; Giove et al., 2009) or by glutamate (Tsumamoto et al., 2002).

First we tested whether the NO donor DETA/NO could alter $\mathrm{I}_{\mathrm{Ca}}$ activation in dissociated Mbs. We found that bath application of DETA/NO (1 mM) resulted in a leftward shift in ramp-evoked $\mathrm{I}_{\mathrm{Ca}} \mathrm{I}-\mathrm{V}$ (Fig. 6A) similar to that seen under control conditions for the second ramp-evoked $\mathrm{I}_{\mathrm{Ca}}$ $\mathrm{I}-\mathrm{V}$ of axotomized $\mathrm{Mb}$ terminals in slice preparation (Fig. 2Bi,Bii). On average, $\mathrm{V}_{(5 \%)}$ was $-41.2 \pm 1.01 \mathrm{mV}$ for control and $-47.5 \pm 2.16 \mathrm{mV}$ for the second ramp $\mathrm{I}-\mathrm{V}, \mathrm{V}_{(50 \%)}$ was $-23.6 \pm 0.74 \mathrm{mV}$ for control and $-28.9 \pm 1.36 \mathrm{mV}$ for the second ramp $\mathrm{I}-\mathrm{V}$, and $\mathrm{V}_{(\mathrm{Max})}$ was $-6.1 \pm 0.99 \mathrm{mV}$ for control and $-10.4 \pm 1.55 \mathrm{mV}$ for the second ramp I-V. On average, the second ramp I-V exhibited an average difference of $-6.3 \pm 1.49 \mathrm{mV}$ for $\mathrm{V}_{(5 \%)},-5.3 \pm 0.84 \mathrm{mV}$ for $\mathrm{V}_{(50 \%)}$, and $-4.3 \pm 0.73 \mathrm{mV}$ for $\mathrm{V}_{(\text {Max })}$. Statistical analysis determined a significant difference in $\mathrm{V}_{(5 \%)}$, $\mathrm{V}_{(50 \%)}$, and $\mathrm{V}_{\text {(Max) }}$ for the ramp I-V obtained in DETA/NO compared with the control $(p=0.002, p=0.0001$, and $p=0.0002$, respectively, paired Student's $t$ test; $n=10$ ).

Next, we examined whether endogenous NO generation and release, triggered by synaptic activity, contribute to the modulation of $\mathrm{I}_{\mathrm{Ca}}$ at $\mathrm{Mb}$ terminals in retinal slice preparation. Specifically, we tested whether pharmacological inhibition of NO production by a nonselective inhibitor of both inducible and neuronal NO synthase (iNOS and nNOS, respectively), TRIM, can reduce the negative shift in $\mathrm{I}_{\mathrm{Ca}}$ activation after depolarizing ramps applied to the $\mathrm{Mb}$ terminals. We found that continuous bath application of TRIM $(50 \mu \mathrm{M})$ eliminated the leftward shift in $\mathrm{I}_{\mathrm{Ca}}$ activation kinetics following ramp depolarization of axotomized $\mathrm{Mb}$ terminals (Fig. 6B). On average, $\mathrm{V}_{(5 \%)}$ was $-42.1 \pm 1.63 \mathrm{mV}$ for control and $-42.5 \pm 2.01 \mathrm{mV}$ for the second ramp I-V, $\mathrm{V}_{(50 \%)}$ was $-27.9 \pm 1.57 \mathrm{mV}$ for control and $-28.63 \pm 1.92 \mathrm{mV}$ for the second $\operatorname{ramp} \mathrm{I}-\mathrm{V}$, and $\mathrm{V}_{(\text {Max })}$ was $-13.75 \pm 1.58 \mathrm{mV}$ for control and $-14.8 \pm 1.90 \mathrm{mV}$ for the second ramp I-V. In the presence of TRIM, there was no significant difference in $\mathrm{V}_{(5 \%)}, \mathrm{V}_{(50 \%)}$, and $\mathrm{V}_{(\mathrm{Max})}$ between control and second ramp evoked $\mathrm{I}_{\mathrm{Ca}} \mathrm{I}-\mathrm{Vs}(p=0.6, p=0.3$, and $p=0.07$, respectively; paired Student's $t$ test; $n=8)$.

Together, these data suggested that the endogenous retinal retrograde messenger responsible for modulation of $\mathrm{I}_{\mathrm{Ca}}$ at $\mathrm{Mb}$ terminals could be NO. The NO donor-evoked shift of $\mathrm{I}_{\mathrm{Ca}}$ acti- 
vation predicted an increase of $\mathrm{I}_{\mathrm{Ca}}$ amplitude in the membrane potential range between $-50 \mathrm{mV}$ and $-20 \mathrm{mV}$, which is physiologically relevant for $\mathrm{Mb}$ function (Saito et al., 1979; Wong et al., 2005). To test this notion directly, we measured depolarization evoked $\mathrm{I}_{\mathrm{Ca}}$ in response to a 10 $\mathrm{ms}$ depolarizing step from $-60 \mathrm{mV}$ to $-30 \mathrm{mV},-20$, or $0 \mathrm{mV}$ along with the depolarization-evoked increase in the membrane capacitance $\left(\Delta \mathrm{C}_{\mathrm{m}}\right)$ of axotomized $\mathrm{Mb}$ terminals under control conditions and after at least $3 \mathrm{~min}$ of continuous bath application of DETA/NO ( $1 \mathrm{~mm})$. We found that bath application of DETA/NO increased the peak $\mathrm{I}_{\mathrm{Ca}}$ in response to a depolarizing step to $-30 \mathrm{mV}$ (Fig. 6C) from $-56.61 \pm$ $11.47 \mathrm{pA}$ to $-96.81 \pm 20.62 \mathrm{pA}$ (Fig. $6 E$; $p=0.004$; paired Student's $t$ test; $n=7$ ). The NO-mediated increase of $\mathrm{I}_{\mathrm{Ca}}$ at -30 $\mathrm{mV}$ was associated with enhanced exocytosis (Fig. 6C; $\mathrm{C}_{\mathrm{m}}$ traces) from an average $\Delta \mathrm{C}_{\mathrm{m}}$ of $26.80 \pm 8.31 \mathrm{fF}$ under control conditions to $32.73 \pm 7.79 \mathrm{fF}$ after application of DETA/NO (Fig. $6 F ; p=0.003$, paired Student's $t$ test; $n=7)$. Treatment with the NO donor also increased the peak $\mathrm{I}_{\mathrm{Ca}}$ in response to steps to $-20 \mathrm{mV}$ (Fig. $6 D)$ from $-165.33 \pm 13.27 \mathrm{pA}$ to $-192.59 \pm 15.62$ pA (Fig. $5 E ; p=0.008$; paired Student's $t$ test, $n=3$ ). However in these terminals, the $\mathrm{I}_{\mathrm{Ca}}$ increase was not associated with an increase in exocytosis $\left(\Delta \mathrm{C}_{\mathrm{m}}: 63.27 \pm 6.45 \mathrm{fF}\right.$ vs $53.46 \pm 3.37 \mathrm{fF}$ in control and in DETA/NO, respectively; Fig. $6 F ; p=0.09$; paired Student's $t$ test; $n=3)$. Neither the control $\mathrm{I}_{\mathrm{Ca}}$ amplitude $(-117.69 \pm 17.15 \mathrm{pA})$ nor the corresponding membrane capacitance increase $\left(\Delta \mathrm{C}_{\mathrm{m}}: 67.99 \pm 1.67 \mathrm{fF}\right)$ was increased by DETA/NO $\left(\mathrm{I}_{\mathrm{Ca}}:-116.69 \pm 31.56 \mathrm{pA}\right.$; $\left.\Delta \mathrm{C}_{\mathrm{m}}: 59.31 \pm 10.54 \mathrm{fF}\right)$ significantly $\left(\mathrm{I}_{\mathrm{Ca}}\right.$ : $p=0.5 ; \Delta \mathrm{C}_{\mathrm{m}}: p=0.2$, paired Student's $t$ test; $n=4)$ in response to depolarizing steps from -60 to $0 \mathrm{mV}$ (Fig. $6 E, F$ ). These results were in perfect agreement with the NO donor evoked leftward shift in $\mathrm{I}_{\mathrm{Ca}}$ activation (Fig. 6A) in that the weaker depolarization evoked voltagegated $\mathrm{I}_{\mathrm{Ca}}$ amplitude was enhanced more. Importantly, these results demonstrated that the $\mathrm{NO}$-induced $\mathrm{I}_{\mathrm{Ca}}$ modulation was reflected in weighted potentiation of glutamate output from $\mathrm{Mb}$ terminals.

NO modulated $\mathrm{I}_{\mathrm{Ca}}$ activation threshold through S-nitrosylation in $\mathrm{Mb}$ terminals Within recent years, NO's role as a retinal signaling molecule has been expanding rapidly (Vielma et al., 2012). The classical intracellular signaling cascade that underlies the effects of NO involves NO detection by soluble guanylate cyclase, which stimulates the production of cGMP. The increased levels of cGMP, in turn,
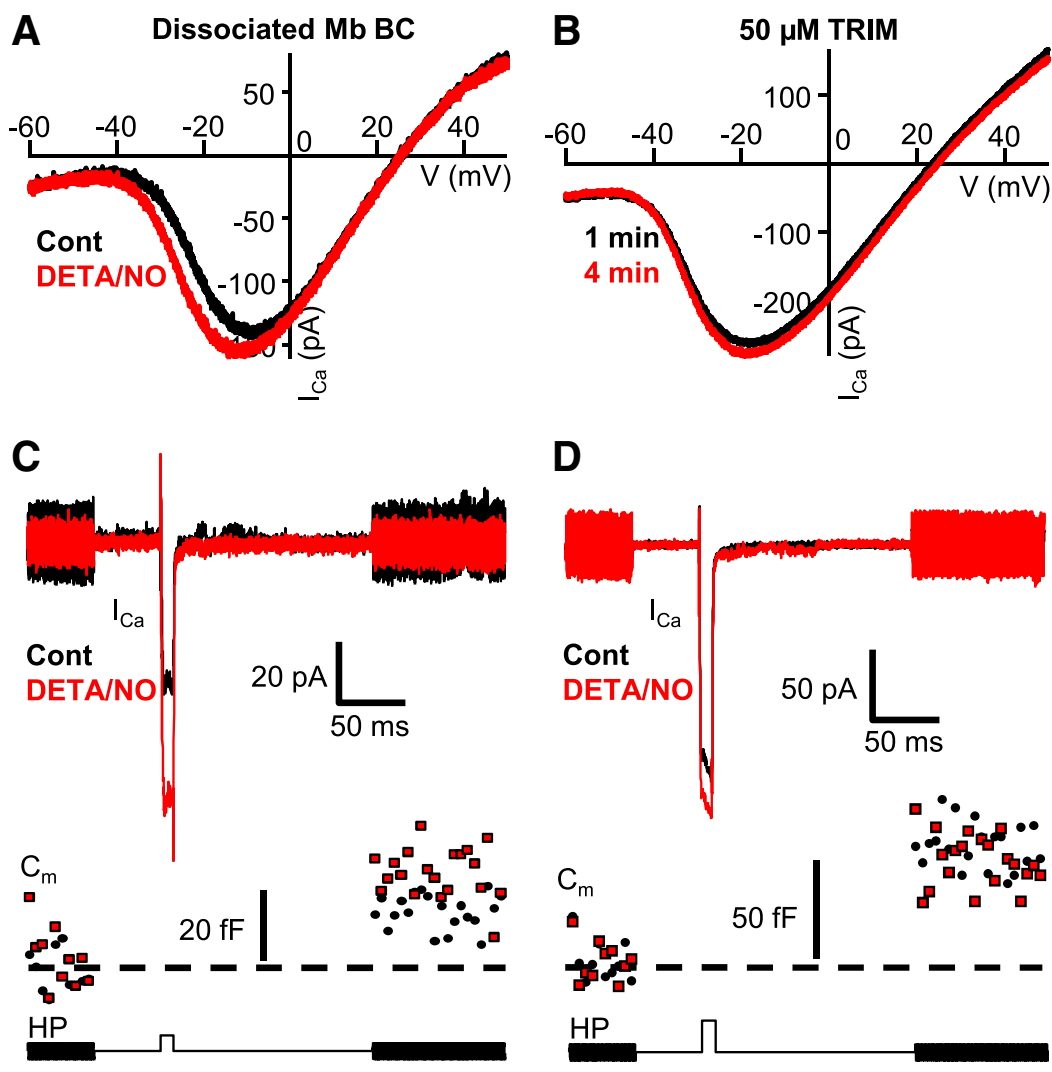

D

E
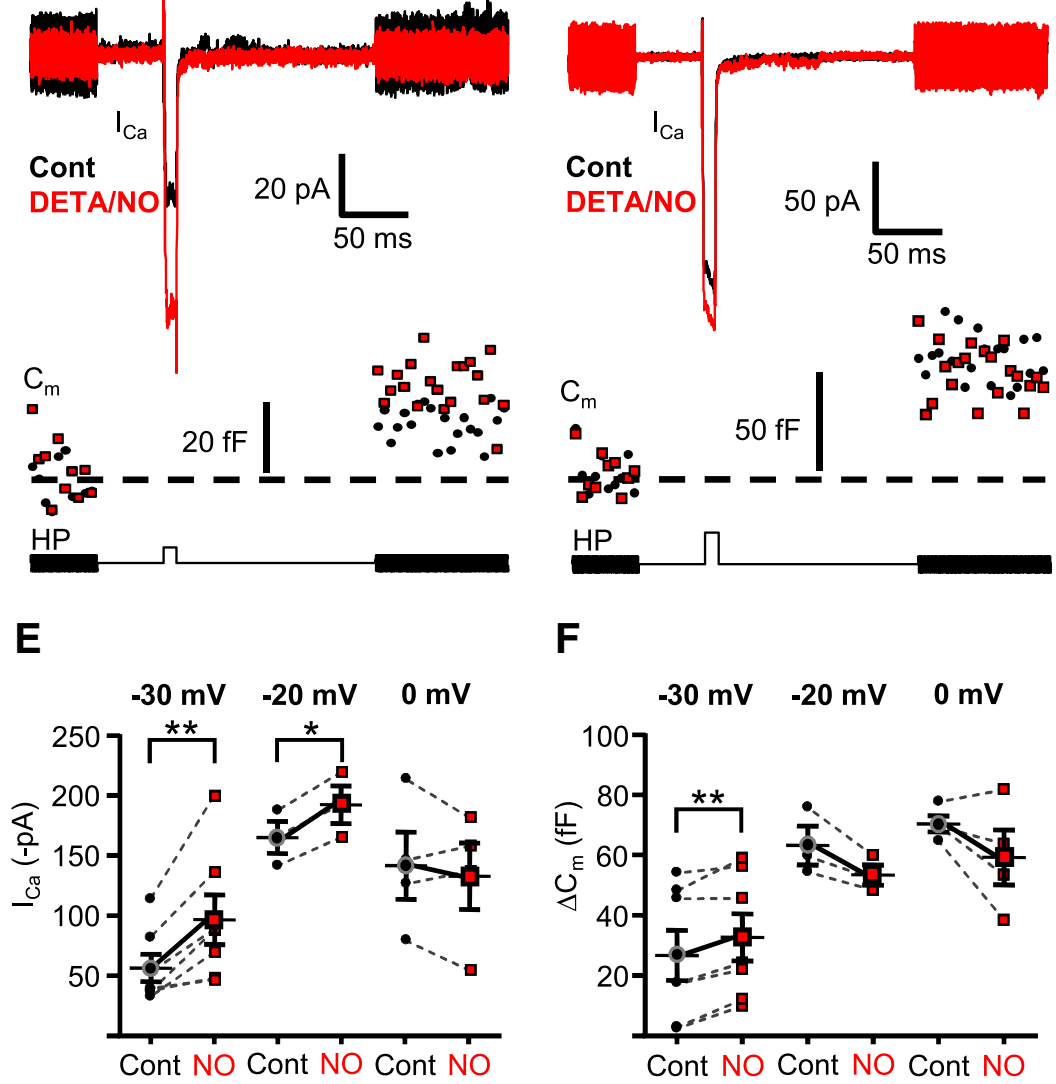

$\mathbf{F}$

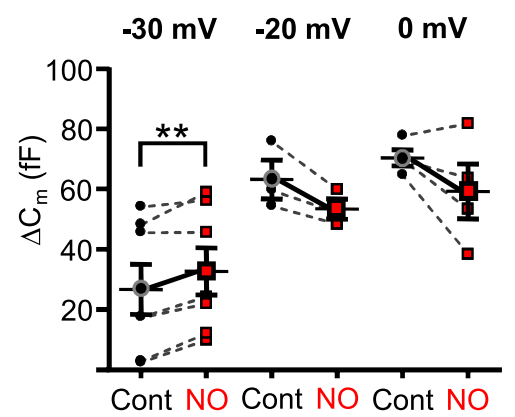

Figure 6. The NO donor-mediated shift of $\mathrm{I}_{\mathrm{Ca}}$ caused weighted potentiation of Mb output selectively in response to weak stimuli.A, Application of NO donor DETA/NO (1 mM) for 1.5 min shifted the ramp-evoked $\mathrm{I}_{\mathrm{Ca}}$ activation to more negative potentials in enzymatically dissociated Mbs (black represents control; red represents DETA/NO). $\boldsymbol{B}$, Inhibition of endogenous $N 0$ synthases by TRIM $(50 \mu \mathrm{M})$ prevented the leftward shift of $\mathrm{I}_{\mathrm{Ca}}$ activation in axotomized $\mathrm{Mb}$ terminals in slice preparation during consecutive ramp stimulations (black represents control; red represents second ramp I-V). C, Bath application of DETA/NO (1 mM) facilitated I $\mathrm{Ca}_{\mathrm{Ca}}$ and enhanced exocytosis $(\mathrm{Cm})$ from the axotomized $\mathrm{Mb}$ terminals in response to a depolarizing step from $-60 \mathrm{mV}$ to $-30 \mathrm{mV}$. HP, Holding potential. Black represents control; red represents DETA/NO treatment. D, Bath application of DETA/NO (1 mM) slightly increased $\mathrm{I}_{\mathrm{Ca}}$, but this increase was not associated with increased exocytosis from axotomized Mb terminals in response to a depolarizing step from $-60 \mathrm{mV}$ to $-20 \mathrm{mV}$ (bottom trace). Black represents control, red represents DETA/NO treatment. $\boldsymbol{E}$, Summary figure displaying DETA/NO (1 mM) effect on peak $\mathrm{I}_{\mathrm{Ca}}$ in response to $10 \mathrm{~ms}$ step from $-60 \mathrm{mV}$ to $-30,-20$, or $0 \mathrm{mV}$. Black circles represent control; red squares represent DETA/NO. ${ }^{* *} p=0.004$ (paired Student's $t$ test). $n=7 .{ }^{*} p=0.008$ (paired Student's $t$ test). $n=3 . F$, Summary figure displaying DETA/NO (1 mM) effect on $\Delta C_{\mathrm{m}}$ evoked by $10 \mathrm{~ms}$ step from $-60 \mathrm{mV}$ to -30 , -20 , or $0 \mathrm{mV}$. Black circles represent control; red squares represent DETA/NO ${ }^{* *} p=0.003$ (paired Student's $t$ test). $n=7 . n=$ 3 for $-20 \mathrm{mV} ; n=4$ for $0 \mathrm{mV}$. Every terminal was tested at one depolarization level in control then in the presence of DETA/NO; thus, each pair of measurements shown originated from different cells. Data are mean \pm SEM.

stimulate protein kinase $\mathrm{G}(\mathrm{PKG})$, resulting in increased transmitter release in cones (Savchenko et al., 1997) and increased sensitivity of cone BCs (Snellman and Nawy, 2004).

To parse out the intracellular pathway associated with modulation of $\mathrm{I}_{\mathrm{Ca}}$ in $\mathrm{Mb}$ terminals by $\mathrm{NO}$, first we attempted to simulate the NO effect in enzymatically dissociated Mbs using the 

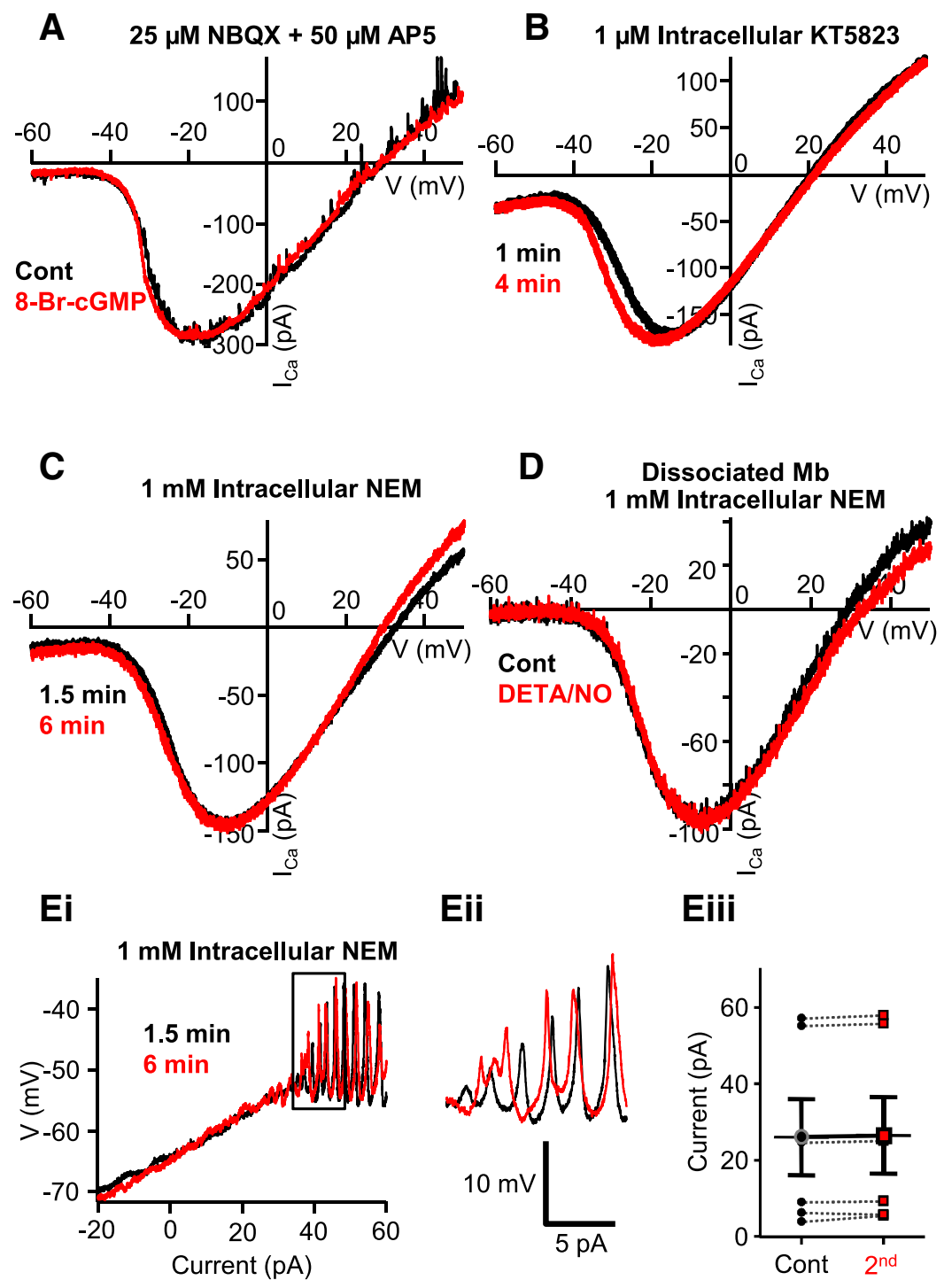

Eiii

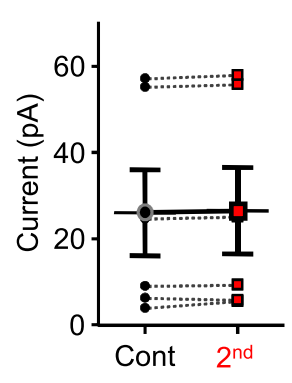

Figure 7. $\mathrm{NO}$ modulated $\mathrm{I}_{\mathrm{Ca}}$ in $\mathrm{Mb}$ terminals through a cGMP-independent pathway that involved S-nitrosylation reactions. $\boldsymbol{A}$ In the presence of NBQX and D-AP5, bath application of the membrane-permeable CGMP analog 8-Br-CGMP (500 $\mu \mathrm{M})$ for 3 min failed to shift $\mathrm{I}_{\mathrm{Ca}}$ activation of axotomized Mb terminals in slice preparation. $\boldsymbol{B}, \mathrm{KT} 5823(1 \mu \mathrm{M})$, a selective inhibitor of PKG, was unable to prevent the shift in $\mathrm{I}_{\mathrm{Ca}}$ activation seen during consecutive ramp stimulations of $\mathrm{Mb}$ terminals in slice preparation. $\boldsymbol{C}$, The leftward shift of the $I_{c a} I-V$ seen during consecutive ramp stimulations of Mb terminals in slice preparation was occluded by intracellular application of NEM (1 mM). $\boldsymbol{D}$, In the presence of NEM (1 mM) in the intracellular solution, the N0 donor, DETA/NO (1 $\mathrm{mm}$ ), did not induce a leftward shift in the $\mathrm{I}_{\mathrm{Ca}}$ activation threshold of dissociated, solitary Mbs. Ei, In the slice preparation, with NEM $(1 \mathrm{~mm})$ in the intracellular solution, no reduction in $\mathrm{Ca}^{2+}$ spike threshold was noticed during consecutive current ramp protocols applied to the axon terminal of Mbs. Eii, enlargement of boxed area in Ei illustrating that initiation threshold for $\mathrm{Ca}^{2+}$ spikes remained similar to that of control when S-nitrosylation reactions were prevented by NEM. Eiii, Summary diagram showing that, in the presence of NEM, no significant change was observed in the depolarizing current threshold of $\mathrm{Ca}^{2+}$ spikes between control and second current ramp-evoked responses. Black circles represent control; red squares represent second; $n=6 ; 4$ intact cells, 2 axotomized pooled. Data are mean \pm SEM.

membrane permeable form of cGMP, 8-Br-cGMP. Application of an external solution containing 8-Br-cGMP $(100-500 \mu \mathrm{M})$ induced a large ("leak") current in 2 of 5 intact Mbs at $-60 \mathrm{mV}$ holding potential, making voltage-ramp evoked $\mathrm{I}_{\mathrm{Ca}} \mathrm{I}$-Vs unreliable and inconsistent in the presence of 8-Br-cGMP (data not shown). These results were consistent with the expression of cyclic nucleotide-gated channels (CNGCs) in Mbs (Henry et al., 2003) that mediate a cation current when activated by focal application of 8-Br-cGMP onto the dendrites of Mbs in retinal slice (Ping et al., 2008). In the rest of the dissociated Mbs (3 of 5), the leak was not increased during 8-Br-cGMP application, which we interpreted as a consequence of potentially damaged dendritic CNGCs. Nonetheless, in those Mbs, 8-Br-cGMP did not alter $\mathrm{I}_{\mathrm{Ca}}$ activation $\left(\mathrm{V}_{(5 \%)}: p=0.9 ; \mathrm{V}_{(50 \%)}\right.$ : $p=0.6 ; \mathrm{V}_{\text {(Max) }}: p=0.7$; paired Student's $t$ test; $n=3$ ). In our hands, 8 -Br-cGMP $(500 \mu \mathrm{M})$ did not induce a current in axotomized $\mathrm{Mb}$ terminals in slice preparation either $\left(\mathrm{I}_{\text {hold }}\right.$ control: $-26.45 \pm 9.67 \mathrm{pA}$ vs cGMP: $-36.92 \pm 16.11 \mathrm{pA}, p=0.4$; paired Student's $t$ test; $n=4$ ), further suggesting that functional CNGCs in Mbs might be restricted to the somatodendritic compartment. More importantly, in the presence of NBQX $(25 \mu \mathrm{M})$ and D-AP5 (50 $\mu \mathrm{M})$ or, in other words, under conditions when the reciprocal endogenous retinal pathway mediating the shift in $\mathrm{I}_{\mathrm{Ca}}$ activation was blocked (Fig. $4 B$ ), 8-Br-cGMP $(500 \mu \mathrm{M})$ did not alter the kinetics of voltage ramp-evoked $\mathrm{I}_{\mathrm{Ca}} \mathrm{I}-\mathrm{Vs}$ (Fig. 7A). Statistical analysis revealed no significant difference between the control and subsequent ramp I-Vs recorded in the presence of 8 - $\mathrm{Br}-\mathrm{cGMP}\left(\mathrm{V}_{(5 \%)}\right.$ : $p=0.9, \mathrm{~V}_{(50 \%)}: p=0.7$ and $\mathrm{V}_{(\text {Max })}: p=$ 0.4 ; paired Student's $t$ test; $n=4)$.

KT5823 was shown to block the NO signaling cascade in retinal neurons by inhibiting PKG (Hirooka et al., 2000; Snellman and Nawy, 2004). Nonetheless, in the presence of $1 \mu \mathrm{M} \mathrm{KT5823}$ in the pipette solution, consecutive depolarizing ramps shifted the $\mathrm{I}_{\mathrm{Ca}}$ activation to the left in axotomized $\mathrm{Mb}$ terminals in slice preparation (Fig. $7 B$ ) similar to what was found under control conditions (Fig. 2Bi,Bii). On average, $\mathrm{V}_{(5 \%)}$ was $-44.0 \pm 1.58 \mathrm{mV}$ for control and $-47.2 \pm 1.77 \mathrm{mV}$ for the second ramp I-V, $\mathrm{V}_{(50 \%)}$ was $-29.5 \pm 1.71 \mathrm{mV}$ for control and $-32.6 \pm 1.73 \mathrm{mV}$ for the second ramp I-V, and $\mathrm{V}_{(\text {Max })}$ was $-15.0 \pm$ $1.95 \mathrm{mV}$ for control and $-18.0 \pm 1.84 \mathrm{mV}$ for the second ramp I-V. The difference in $\mathrm{I}_{\mathrm{Ca}} \mathrm{I}-\mathrm{V}$ curve parameters $\left(\mathrm{V}_{(5 \%)}:-3.2 \pm\right.$ $0.37 \mathrm{mV} ; \mathrm{V}_{(50 \%)}:-3.1 \pm 0.19 \mathrm{mV}$; and $\left.\mathrm{V}_{(\text {Max })}:-3.0 \pm 0.32 \mathrm{mV}\right)$ was statistically significant $\left(\mathrm{V}_{(5 \%)}: p=0.001 ; \mathrm{V}_{(50 \%)}: p=\right.$ $0.00007 ; \mathrm{V}_{(\mathrm{Max})}: p=0.0006$; paired Student's $t$ test; $n=5$ ).

These findings discounted the role of an NO-stimulated cGMP-dependent pathway in altering $\mathrm{I}_{\mathrm{Ca}}$ activation at $\mathrm{Mb}$ terminals and are in concert with the report showing that $\mathrm{NO}$ donor application failed to trigger cGMP elevation in Mbs in the goldfish retina (Baldridge and Fischer, 2001). An alternative mechanism of action by which NO can influence cellular function is through direct nitrosylation, in which $\mathrm{NO}$ covalently binds to the thiol side-chains of cysteine residues of various proteins to form S-nitrosothiols (Snitrosylation) (for review, see Ahern et al., 2002). To assess whether NO-mediated S-nitrosylation played a role in the observed leftward shift of $\mathrm{I}_{\mathrm{Ca}}$ activation in response to ramp I-Vs of axotomized $\mathrm{Mb}$ terminals, we introduced NEM (1 mM) into the 
intracellular solution. NEM is a potent inhibitor of $\mathrm{S}$-nitrosylation as it irreversibly reacts with and binds to sulfhydryl groups thereby preventing $\mathrm{NO}$ from engaging in an $S$-nitrosylation reaction. NEM prevented the leftward shift of $\mathrm{I}_{\mathrm{Ca}}$ during consecutive voltage ramps in axotomized $\mathrm{Mb}$ terminals in retinal slice (Fig. $7 C$ ). On average, $\mathrm{V}_{(5 \%)}$ was $-43.2 \pm 0.92 \mathrm{mV}$ for control and $-44.0 \pm 1.14 \mathrm{mV}$ for the second ramp $\mathrm{I}-\mathrm{V}, \mathrm{V}_{(50 \%)}$ was $-28.5 \pm 0.71 \mathrm{mV}$ for control and $-27.6 \pm 0.54 \mathrm{mV}$ for the second ramp $\mathrm{I}-\mathrm{V}$, and $\mathrm{V}_{(\mathrm{Max})}$ was $-12.6 \pm 0.68 \mathrm{mV}$ for control and $-11.6 \pm 1.12 \mathrm{mV}$ for the second ramp I-V. Statistical analysis determined no significant difference in $\mathrm{V}_{(5 \%)}, \mathrm{V}_{(50 \%)}$, and $\mathrm{V}_{\text {(Max) }}$ between the control and second ramp evoked $\mathrm{I}_{\mathrm{Ca}} \mathrm{I}-\mathrm{Vs}$ ( $p=0.7, p=0.9$, and $p=0.4$, respectively; paired Student's $t$ test; $n=5)$. Similarly, in the presence of NEM ( $1 \mathrm{mM})$ in the pipette solution, bath application of $1 \mathrm{~mm}$ DETA/NO (Fig. 7D) failed to alter the parameters of voltage ramp evoked $\mathrm{I}_{\mathrm{Ca}} \mathrm{I}-\mathrm{V}$ in enzymatically dissociated Mbs. On average, $\mathrm{V}_{(5 \%)}$ was $-41.5 \pm 1.26 \mathrm{mV}$ for control and $-41.8 \pm 0.87 \mathrm{mV}$ for the second ramp $\mathrm{I}-\mathrm{V}, \mathrm{V}_{(50 \%)}$ was $-25.3 \pm 1.45 \mathrm{mV}$ for control and $-25.7 \pm 1.41 \mathrm{mV}$ for the second ramp $\mathrm{I}-\mathrm{V}$, and $\mathrm{V}_{(\mathrm{Max})}$ was $-9.2 \pm 2.32 \mathrm{mV}$ for control and $-9.7 \pm 2.54 \mathrm{mV}$ for the second ramp I-V. Statistical analysis revealed no difference between control and second ramp I-V parameters $\left(\mathrm{V}_{(5 \%)}: p=0.8 ; \mathrm{V}_{(50 \%)}: p=0.7\right.$ and $\mathrm{V}_{(\text {Max })}: p=0.6$, paired Student's $t$ test; $n=6$ ).

Last, we assessed whether preventing S-nitrosylation in $\mathrm{Mb}$ terminals also prevents the shift in $\mathrm{Ca}^{2+}$ spike threshold observed during stimulation of $\mathrm{Mb}$ terminals with consecutive depolarizing current ramps (Fig. 1). We found that blocking $\mathrm{S}$-nitrosylation of proteins within the Mb terminal with NEM prevented a change in the threshold for $\mathrm{Ca}^{2+}$ spike initiation (Fig. 7Ei). An enlargement of the region of the trace where the spikes begin to originate shows no obvious difference in the threshold for initiation (Fig. 7Eii). On average, initiation of spikes during the first (control) ramp required $25.92 \pm 9.98 \mathrm{pA}$, almost identical to that required during the second ramp applied $3 \mathrm{~min}$ later $(26.47 \pm 10.03 \mathrm{pA})$, and no significant difference between the thresholds of calcium spikes were detected $(p=0.1$, paired Student's $t$ test, $n=6$; 4 intact cells, 2 axotomized terminals; Fig. 7Eiii). Further, there was no shift in the membrane potential associated with the spike threshold. With $1 \mathrm{mM}$ NEM in the internal solution, on average, spikes initiated at $-45.35 \pm 2.46 \mathrm{mV}$ for control and at $-44.82 \pm 2.73 \mathrm{mV}$ for the second trace $(p=$ 0.4 , paired Student's $t$ test, $n=6$; 4 intact cells, 2 axotomized terminals).

\section{Light induced NEM-sensitive modulation of Mbs response to scotopic, rod-mediated inputs in an intensity-dependent manner}

Although direct nitrosylation of thiol side-chains of cysteine residues by NO plays an important role in numerous physiological processes (Ahern et al., 2002), it is a particularly important process in neurodegenerative diseases (Nakamura et al., 2013). Our results presented until this point show that this pathway can be triggered by endogenous, synaptically released glutamate, which initiates retrograde modulation of $\mathrm{I}_{\mathrm{Ca}}$ at the same presynaptic $\mathrm{BC}$ axon terminals. Nonetheless, the depolarizing ramp protocols that were shown to trigger this pathway consistently in our experiments were far from physiologically relevant depolarizations for Mbs. To study whether our findings have functional consequences for normal visual processing or whether this NOmediated process can only exist under experimental conditions in retina, we designed a set of experiments where depolarizations of Mbs were evoked by light stimulations, based on the observa- tion that: (1) NO release in the retina is triggered by increasing light intensity (Eldred and Blute, 2005; Giove et al., 2009); (2) our preceding experiments suggesting that small depolarizations of $\mathrm{Mb}$ terminals might be preferentially potentiated by endogenous $\mathrm{NO}$, which appeared to be released in our prep by large synaptic depolarizations of inner retinal neurons (Figs. 2Bi and 5); and (3) magnitude of depolarization in ON BCs is related to strength and wavelength of illumination (Joselevitch and Kamermans, 2007; Jarsky et al., 2011). Although we did not intend to simulate Mb responses to natural underwater visual scenes, the wavelength and intensity of light stimulations were selected to match those behaviorally relevant in shallow water (Munz and McFarland, 1973; McFarland and Munz, 1975; Loew and McFarland, 1990). Additionally, the light stimulations were chosen in accordance with the observations that Mbs in the fish retina receive direct inputs from both rods and cones (Wong et al., 2005; Joselevitch and Kamermans, 2007), similar to many BCs in cold-blooded vertebrate retinas $(\mathrm{Wu}, 1994)$ and certain mammalian BCs (Protti et al., 2005; Haverkamp et al., 2008; Pang et al., 2010).

In these experiments, light-evoked responses of intact Mbs were recorded directly from their axon terminals in currentclamp mode from dark-adapted retinal slices. Mbs were slightly hyperpolarized to keep their membrane potential at $\sim-51 \mathrm{mV}$, which prevented spontaneous $\mathrm{Ca}^{2+}$ spike firing in the dark. Figure $8 A i$ shows representative control responses recorded form the axon terminal of an intact $\mathrm{Mb}$, evoked by two sets of 3 consecutive $\operatorname{dim}\left(1.6 \times 10^{7}\right.$ photons $\left./ \mathrm{cm}^{2} / \mathrm{s}\right)$ green flashes $(\lambda=505$ $\mathrm{nm}, 500 \mathrm{~ms}$ ) applied $5 \mathrm{~s}$ apart and with $4 \mathrm{~min}$ between the two sets of light stimuli. The responses to the same light stimulation showed great variability in the number and amplitude of the $\mathrm{Ca}^{2+}$ spikes (Fig. $8 \mathrm{Ai}$ ), but they were rather consistent in terms of the latency within sets as well as across consecutive sets (Fig. 8Aii): for the Mb shown, the latency of first light-evoked spikes varied between 245 and $258 \mathrm{~ms}$, averaging at $251.33 \pm 3.76 \mathrm{~ms}$ for the first set and varied between 249 and $250 \mathrm{~ms}$ averaging at $249.67 \pm 0.3 \mathrm{~ms}$ for the second set of stimulations (Fig. 8Aiii). When latencies of these $\operatorname{dim}$ green light $\left(1.6 \times 10^{7}\right.$ photons/ $\mathrm{cm}^{2} / \mathrm{s}, \lambda=505 \mathrm{~nm}, 500 \mathrm{~ms}$ ) evoked spikes between the first and second sets $(248.6 \pm 14.6 \mathrm{~ms}$ vs $247.02 \pm 13.8 \mathrm{~ms}$, respectively) were compared across multiple cells $(n=6)$, we found no significant statistical difference ( $p=0.6$, paired Student's $t$ test).

In the next set of experiments, we devised a protocol with the intent to determine whether the Mb spiking response could be sensitized by light. The general framework of the light stimulation consisted of an initial light flash, followed by a brighter, "sensitizing" light flash, and then a repeat presentation of the initial flash. This paradigm allowed us to compare the lightevoked spiking response of the $\mathrm{Mb}$ terminal before and after a sensitizing light stimulus and use the observed differences as a metric for whether or not the terminal had been "sensitized." Specifically, the retina was exposed to a series of full field green $(\lambda=505 \mathrm{~nm})$ light flashes $(500 \mathrm{~ms})$ with increasing intensities ranging from scotopic $\left(7 \times 10^{6}\right.$ photons $\left./ \mathrm{cm}^{2} / \mathrm{s}\right)$ to $\mathrm{dim}$ photopic $\left(1.2 \times 10^{11}\right.$ photons $\left./ \mathrm{cm}^{2} / \mathrm{s}\right)$ intensities (Busskamp et al., 2010). Then a $500 \mathrm{~ms}$ bright red light (sensitizing) stimulus $(\lambda=660$ $\mathrm{nm}, 5 \times 10^{13}$ photons $/ \mathrm{cm}^{2} / \mathrm{s}$ ) was delivered. With a minimum delay of 5 min after the red light flash, the series of (initial) green light flashes were repeated. Figure $8 \mathrm{Bi}$ shows a representative recording where we found that the second dim green flash $(1.6 \times$ $10^{7}$ photons $/ \mathrm{cm}^{2} / \mathrm{s}$ ), applied after sensitizing red stimulation, triggered a spiking response from the $\mathrm{Mb}$ axon terminal with shorter delay compared with that evoked by the same intensity before the red flash (Fig. $8 B i, B i i)$ as if the terminal was "sensi- 
Ai

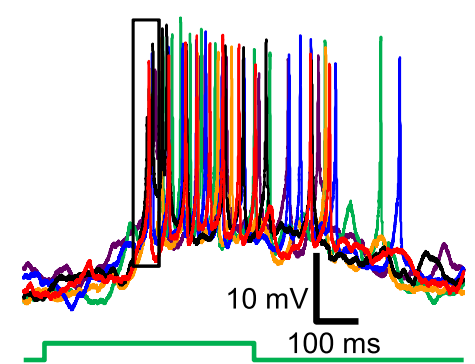

$1.6 \times 10^{7}$ photons $/ \mathrm{cm}^{2} / \mathrm{s}$

$\mathrm{Bi}$

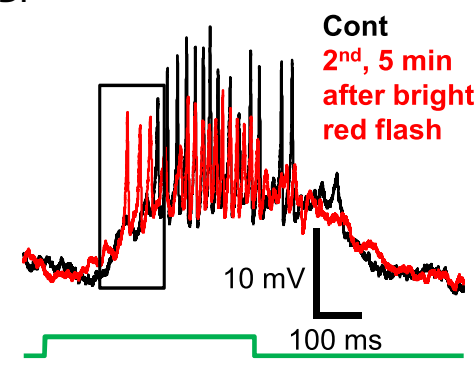

$1.6 \times 10^{7}$ photons $/ \mathrm{cm}^{2} / \mathrm{s}$

$\mathrm{Ci}$

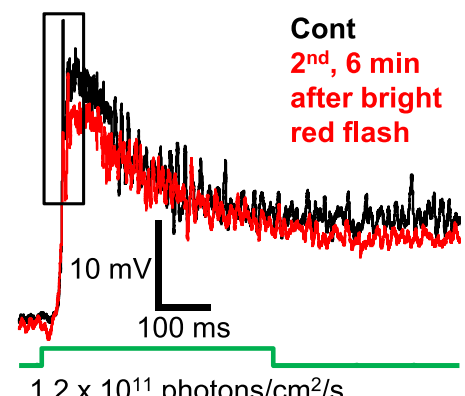

Cont

$2^{\text {nd }}, 6 \mathrm{~min}$ after bright red flash

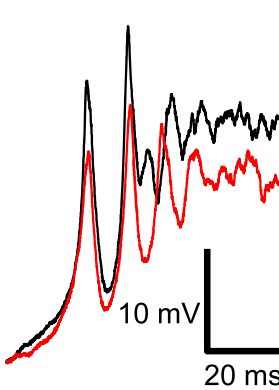

Cii

Aiii

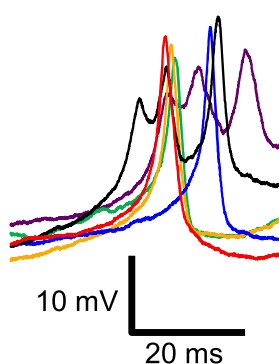

Bii

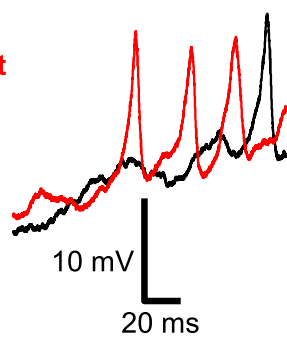

Biii

Ciii
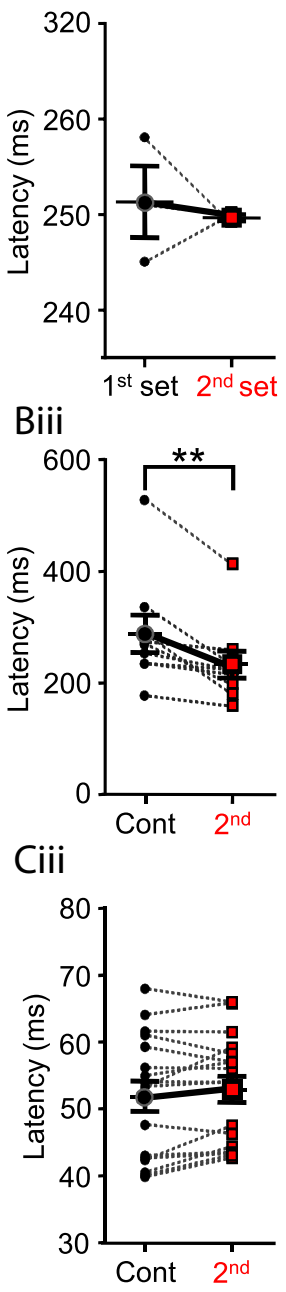

D

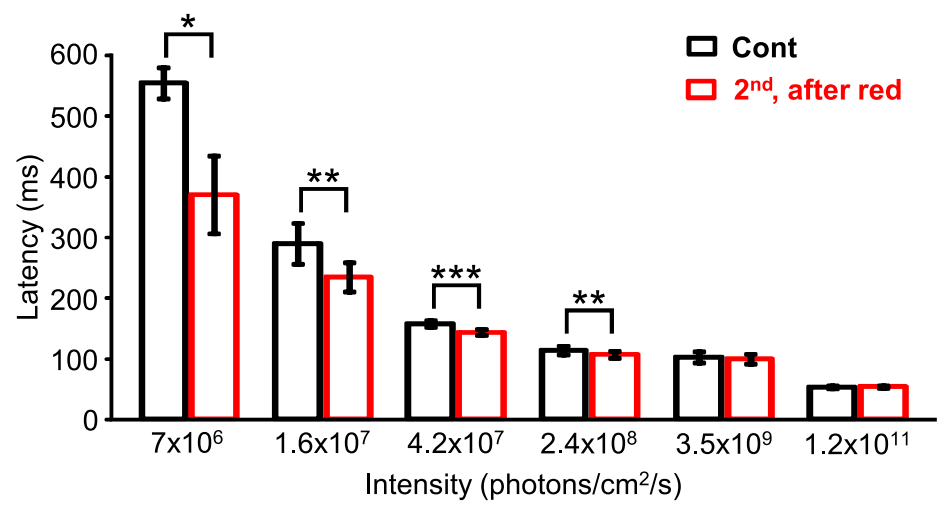

Figure 8. Photopic light stimulation modulated scotopic light responses of $\mathrm{Mb}$ axon terminals. Ai, Repeated stimulations of rod-specific scotopic green light flashes $\left(500 \mathrm{~ms}, \lambda=505 \mathrm{~nm}, 1.6 \times 10^{7}\right.$ photons $\left./ \mathrm{cm}^{2} / \mathrm{s}\right)$ did not significantly alter the latency of evoked $\mathrm{Ca}^{2+}$ spikes from the axon terminal of an intact Mb. The first set of responses (black, blue, and green traces) were evoked by three distinct flashes of dim green light with a 5 s delay between flashes. After a 4 min delay, a second set of responses (purple, red, and orange traces) was evoked by three distinct flashes of dim green light. Membrane potentials at the beginning of the traces are $-51.8 \mathrm{mV}$ (black), $-48.9 \mathrm{mV}$ (blue), $-52.4 \mathrm{mV}$ (green), $-47.9 \mathrm{mV}$ (purple), $-50.8 \mathrm{mV}$ (red), and $-52.1 \mathrm{mV}$ (orange). Aii, Enlargement of boxed area in Ai illustrating consistency in the latency of scotopic green light-induced $\mathrm{Ca}^{2+}$ spikes. Membrane potentials at the beginning of the traces are $-44.6 \mathrm{mV}$ (black), $-44.7 \mathrm{mV}$ (blue), $-43.3 \mathrm{mV}$ (green), $-41.9 \mathrm{mV}$ (purple), -44.6 $\mathrm{mV}$ (red), and $-46.6 \mathrm{mV}$ (orange). Aiii, Summary graph showing paired comparison of latency to first spikes of corresponding responses triggered by the first and second set of dim green $\left(505 \mathrm{~nm}, 1.6 \times 10^{7}\right.$ photons $\left./ \mathrm{cm}^{2} / \mathrm{s}\right)$ light flashes. The latency to first spike was not significantly different between sets. Black circles represent first set; red squares represent second set. Bi, Rodmediated scotopic green $\left(505 \mathrm{~nm}, 1.6 \times 10^{7}\right.$ photons $\left./ \mathrm{cm}^{2} / \mathrm{s}\right)$ full-field light flash $(500 \mathrm{~ms})$ evoked responses recorded from the axon terminal of an intact $\mathrm{Mb}$, in dark-adapted retina slice preparation (black), were modulated by bright red light stimulation (500 tized" by the bright red light stimulation. Similar shortening of first spike delay was seen in every cell tested ( 9 of 9; Fig. 8Biii) at this green light intensity and was found to be statistically significant ( $p=0.006$, paired Student's $t$ test). Interestingly, the delay of light responses to bright $(1.2 \times$ $10^{11}$ photons $/ \mathrm{cm}^{2} / \mathrm{s}$ ) green light of the same $\mathrm{Mb}$ was not different before and after the bright red simulation (Fig. $8 \mathrm{Ci}$ ,Cii). Across cells, the latency to first spike increased in 7 of $17 \mathrm{Mbs}$, decreased in 6 of 17 , and remained virtually unaltered in 4 of 17 cells (Fig. 8Ciii); and when summed, no statistically significant difference was detected ( $p=0.1$, paired Student's $t$ test, $n=17$ ). Of the six different intensities of green light presented in this set of experiments, a significant decrease in latency was observed in those under intensities

$\mathrm{ms}, 660 \mathrm{~nm}, 5 \times 10^{13}$ photons $/ \mathrm{cm}^{2} / \mathrm{s}$, Mb response not shown here; but see Fig. $9(i)$. Five minutes after the bright red flash, the repeated dim green stimulus evoked spiking response with decreased latency (red trace) compared with control. Membrane potential at the beginning of both traces was $-51 \mathrm{mV}$. Bii, Enlargement of boxed area in Bi illustrating the decreased latency of scotopic green light-induced $\mathrm{Ca}^{2+}$ spikes, after the bright red stimulation. Membrane potentials at the beginning of traces are $-50.5 \mathrm{mV}$ (red) and $-52.8 \mathrm{mV}$ (black). Biii, Summary graph showing paired comparison of latency to first spike triggered by dim green $(505 \mathrm{~nm}, 1.6 \times$ $10^{7}$ photons $/ \mathrm{cm}^{2} / \mathrm{s}$ ) flash before and after presentation of bright red light recorded from different Mb terminals. The latency to first spike was significantly reduced for the second stimulus, on average by $55.18 \pm 14.98 \mathrm{~ms}$. Black circles represent control; red squares represent second scotopic response latency. ${ }^{* *} p=0.006$ (paired Student's $t$ test). $n=9$. Ci, Responses of Mb terminal to mesopic green $(500 \mathrm{~ms}, 505 \mathrm{~nm}$, $1.2 \times 10^{11}$ photons $/ \mathrm{cm}^{2} / \mathrm{s}$ ) light flashes, before (black) and 5 min after (red) the bright red flash $\left(660 \mathrm{~nm}, 5 \times 10^{13} \mathrm{pho}\right.$ tons $/ \mathrm{cm}^{2} / \mathrm{s}, 500 \mathrm{~ms}$, Mb response not shown). No difference in the delay of mesopic light responses was noticeable. Membrane potential at the beginning of the traces was $-52 \mathrm{mV}$. Cii, Enlargement of boxed area in Ci illustrating no apparent difference in the latency of scotopic green light-induced $\mathrm{Ca}^{2+}$ spikes, after the bright red stimulation. Membrane potentials at the beginning of traces are $-50.25 \mathrm{mV}$ (red) and -50.1 $\mathrm{mV}$ (black). Ciii, Summary graph of paired comparison of mesopic green light (500 ms, $505 \mathrm{~nm}, 1.2 \times 10^{11}$ photons/ $\mathrm{cm}^{2} / \mathrm{s}$ ) response latency before and after presentation of bright red light. No significant difference was detected. Black circles represent control; red squares represent second scotopic response latency. $n=17$. D, Summary graph showing the average latency to first spike from green light responses triggered by six intensities before (black) and 5 min after (red) bright red stimulation. Of the six different intensities of green light presented, a significant decrease in latency was observed in response to dim, scotopic intensities known to stimulate rods, but not cones $\left(\leq 3.5 \times 10^{9}\right.$ photons $\left./ \mathrm{cm}^{2} / \mathrm{s}\right): 7 \times 10^{6}$ photons $/ \mathrm{cm}^{2} / \mathrm{s} ; n=3$. ${ }^{*} p=0.04 .1 .6 \times 10^{7}$ photons $/ \mathrm{cm}^{2} / s ; n=9 .{ }^{* *} p=0.006$. $4.2 \times 10^{7}$ photons $/ \mathrm{cm}^{2} / \mathrm{s} ; n=17$. ${ }^{* * *} p=0.0001 .2 .4 \times 10^{8}$ photons $/ \mathrm{cm}^{2} / \mathrm{s} ; n=17 .{ }^{* *} p=0.02 .3 .5 \times 10^{9}$ photons $/ \mathrm{cm}^{2} / \mathrm{s}$; $n=17.1 .2 \times 10^{11}$ photons $/ \mathrm{cm}^{2} / \mathrm{s}: n=17$ (paired Student'st test). Data are mean \pm SEM. 
known to stimulate only rods $\left(\leq 10^{8}\right.$ photons $\left./ \mathrm{cm}^{2} / \mathrm{s}\right)$ and was not observed in intensities above cone threshold $\left(\sim 10^{9}\right.$ photons/ $\mathrm{cm}^{2} / \mathrm{s}$ in the goldfish retina) (Joselevitch and Kamermans, 2009). The dimmest green light stimulus used in our experiments $(7 \times$ $10^{6}$ photons $/ \mathrm{cm}^{2} / \mathrm{s}$ ) produced a spiking response with an average latency of $553.50 \pm 25.74 \mathrm{~ms}$ in control (first) and with $369.37 \pm$ $63.80 \mathrm{~ms}$ after the red flash (second); in response to a $1.6 \times 10^{7}$ photons $/ \mathrm{cm}^{2} / \mathrm{s}$ flash, the average latency was $288.71 \pm 33.36 \mathrm{~ms}$ in control (first) and $233.54 \pm 24.44$ after the red flash (second); in response to a $4.2 \times 10^{7}$ photons $/ \mathrm{cm}^{2} / \mathrm{s}$ flash, the average latency was $156.92 \pm 5.12 \mathrm{~ms}$ in control (first) and $142.55 \pm 4.69$ after the red flash (second); in response to a $2.4 \times 10^{8}$ photons/ $\mathrm{cm}^{2} / \mathrm{s}$ flash, the average latency was $112.99 \pm 7.19 \mathrm{~ms}$ in control (first) and $105.93 \pm 5.97$ after the red flash (second); in response to a $3.5 \times 10^{9}$ photons $/ \mathrm{cm}^{2} / \mathrm{s}$ flash, the average latency was $101.57 \pm 8.59 \mathrm{~ms}$ in control (first) and $98.85 \pm 7.99$ after the red flash (second); in response to a $1.2 \times 10^{11}$ photons $/ \mathrm{cm}^{2} / \mathrm{s}$ flash, the latency was $51.89 \pm 2.24 \mathrm{~ms}$ in control (first) and $52.93 \pm$ 1.97 after the red flash (second) (Fig. 8D). The latency, as well as the variability in latency across cells, decays as light intensity increases. These results are consistent with the observation that temporal precision of spikes produced by BCs, evoked by highcontrast light stimulation, is in the millisecond range, which correlates with that of AC and GC spikes in the fish retina (Baden et al., 2011).

The intensity of sensitizing light stimulus used in the previous experiment was sufficient to activate both rod and cone inputs to Mbs (Joselevitch and Kamermans, 2007). In the next set of experiments, we sought to parse out the contribution of rod- and conemediated signaling in triggering the light-induced sensitization of $\operatorname{dim}$ scotopic light $\left(\lambda=505 \mathrm{~nm}, 500 \mathrm{~ms}, 1.6 \times 10^{7}\right.$ photons/ $\mathrm{cm}^{2} / \mathrm{s}$ ) responses. This particular scotopic intensity was selected as it reliably evoked spiking responses in Mbs with relatively high temporal precision (Fig. $8 A$ i,Aii) and exhibited a latency that did not change over the time course $(\sim 5 \mathrm{~min})$ of these experiments (Fig. 8Aiii). However, the latency of responses to this scotopic intensity showed significant reduction, after bright red sensitizing light stimulation, consistently across cells (Fig. 8Biii). We found that a full field green flash $(\lambda=505 \mathrm{~nm}, 500 \mathrm{~ms})$ with an intensity of $2.4 \times 10^{8}$ photons $/ \mathrm{cm}^{2} / \mathrm{s}$, which is just below cone threshold in the fish retina (Joselevitch and Kamermans, 2009), could also reduce the latency of consecutive light responses evoked by the dim scotopic green flash. On average, the latencies of the spiking response were reduced from $281.12 \pm 11.28 \mathrm{~ms}$ to $249.86 \pm 10.75 \mathrm{~ms}$ (Fig. 9Ai,Aii) reliably (in 11 of 11 experiments, Fig. 9Aiii), and the reduction was proven statistically significant $(p=0.0001$, paired Student's $t$ test, $n=11)$. In the next experiments, we increased the sensitizing green flash $(\lambda=505 \mathrm{~nm}, 500$ $\mathrm{ms}$ ) stimulus intensity to $10^{10}$ photons $/ \mathrm{cm}^{2} / \mathrm{s}$. This mesopic intensity saturates rods (Sterling, 2003; Busskamp et al., 2010) and starts to activate cones (Joselevitch and Kamermans, 2009). As expected, flashes at this intensity also reduced the latency of consecutive dim green, flash-evoked responses in every cell tested (Fig. 9Bi,Bii) (control: $275.29 \pm 9.41 \mathrm{~ms}$ vs second: $230.84 \pm$ $10.17 \mathrm{~ms})$ in a statistically significant manner $(p=0.00008$, paired Student's $t$ test, $n=7$ ) (Fig. 9Biii). Compared across experiments, we found that the reduction of dim scotopic green $\left(\lambda=505 \mathrm{~nm}, 500 \mathrm{~ms}, 1.6 \times 10^{7}\right.$ photons $\left./ \mathrm{cm}^{2} / \mathrm{s}\right)$ response latencies triggered by the sensitizing light was intensity-dependent: it was the largest $(55.18 \pm 14.98 \mathrm{~ms}, n=9)$ for bright photopic red $\left(\lambda=660 \mathrm{~nm}, 500 \mathrm{~ms}, 5 \times 10^{13}\right.$ photons $\left./ \mathrm{cm}^{2} / \mathrm{s}\right)$, followed by the reduction of ( $44.44 \pm 4.71 \mathrm{~ms}, n=7)$ caused by rod-saturating mesopic green $\left(\lambda=505 \mathrm{~nm}, 500 \mathrm{~ms}, 10{ }^{10}\right.$ photons $\left./ \mathrm{cm}^{2} / \mathrm{s}\right)$ flashes and was the smallest $(31.25 \pm 3.12 \mathrm{~ms}, n=11)$ for bright scotopic green $\left(\lambda=505 \mathrm{~nm}, 500 \mathrm{~ms}, 2.4 \times 10^{8}\right.$ photons $\left./ \mathrm{cm}^{2} / \mathrm{s}\right)$ stimuli. However, when the latency changes caused by these three sensitizing light stimulations were statistically analyzed, no significant difference was detected among them (one-way ANOVA, with Tukey's multiple-comparison test). These results indicated that bright scotopic signals, which are processed and conveyed to the inner retina by Mbs, were sufficient to potentiate processing of consecutive weak rod inputs by Mbs. Light stimuli bright enough to activate cones might trigger further activity-dependent weighted potentiation of $\mathrm{Mb}$ signaling. Together, the data demonstrated that the strength of $\mathrm{Mb}$ depolarization drove the retrograde, $\mathrm{NO}$-mediated modulation of $\mathrm{Mb}$ terminal signaling.

Next, we tested whether similar modulatory mechanism affects photopic signals processed by Mbs; specifically, we tested whether weak photopic responses of $\mathrm{Mb}$ terminals evoked by red flashes $\left(\lambda=660 \mathrm{~nm}, 500 \mathrm{~ms}, 1.2 \times 10^{11}\right.$ photons $\left./ \mathrm{cm}^{2} / \mathrm{s}\right)$ can be also sensitized by bright photopic stimulation $(\lambda=660 \mathrm{~nm}, 500$ $\mathrm{ms}, 5 \times 10^{13}$ photons $\left./ \mathrm{cm}^{2} / \mathrm{s}\right)$ in a similar manner. When delivered on a dark background, the weak photopic red $(\lambda=660 \mathrm{~nm}$, $500 \mathrm{~ms}, 1.2 \times 10^{11}$ photons $\left./ \mathrm{cm}^{2} / \mathrm{s}\right)$ and the rod-saturating green $\left(\lambda=505 \mathrm{~nm}, 10^{10}\right.$ photons $\left./ \mathrm{cm}^{2} / \mathrm{s}\right)$ stimulation evoked identical responses in $\mathrm{Mb}$ terminals (Fig. $9 \mathrm{Ci}$ and $9 \mathrm{Cii}$, respectively): the spikes merged into a transient initial depolarization that was followed by a depolarized plateau with superimposed small spikes/ membrane potential oscillations, which exceeded the length of the illumination. The membrane potential of the plateau varied between $-33.25 \mathrm{mV}$ and $-40.05 \mathrm{mV}$ and averaged $-37.22 \pm$ $2.41 \mathrm{mV}(n=7)$. To isolate cone responses, red flashes were delivered on a rod-saturating green background $(\lambda=505 \mathrm{~nm}$, $10{ }^{10}$ photons $\left./ \mathrm{cm}^{2} / \mathrm{s}\right)$, which was turned on $4 \mathrm{~s}$ before the first red stimulations. Neither weak $\left(1.2 \times 10^{11}\right.$ photons $\left./ \mathrm{cm}^{2} / \mathrm{s}\right)$ nor strong $\left(5 \times 10^{13}\right.$ photons $\left./ \mathrm{cm}^{2} / \mathrm{s}\right)$ photopic red stimulation $(\lambda=$ $660 \mathrm{~nm}, 500 \mathrm{~ms}$ ), when superimposed on the rod-saturating green background, evoked detectable responses (Fig. 9Ciii). These results remain consistent with the observation that Mbs process rod-dominant visual signals and nearly saturate at intensities of $10{ }^{10}$ photons $/ \mathrm{cm}^{2} / \mathrm{s}$ (Joselevitch and Kamermans, 2009).

Collectively, these data suggested that the latency of lightevoked $\mathrm{Ca}^{2+}$ spikes in $\mathrm{Mb}$ terminals is subject to plasticity; in our experimental protocol, a flash of light with intensity $\geq 2.4 \times 10^{8}$ photons $/ \mathrm{cm}^{2} / \mathrm{s}$ shortened the latency, especially for $\mathrm{Ca}^{2+}$ spikes evoked by scotopic light intensities. This pattern closely resembled what was reported for $\mathrm{NO}$-mediated changes in cone $\mathrm{BC}$ sensitivity in mammalian retinas: $\mathrm{NO}$ increased $\mathrm{BC}$ sensitivity to weak inputs but did not alter strong ones (Snellman and Nawy, 2004). However, our results could also be explained by an NOmediated effect localized to the Mb terminals, in which $\mathrm{NO}$ via $\mathrm{S}$-nitrosylation reaction caused a shift in $\mathrm{I}_{\mathrm{Ca}}$ activation that resulted in reduction of $\mathrm{Ca}^{2+}$ spike threshold, leading to shortened first spike delay in response to weak inputs.

To test this notion directly, we repeated previous experiments where we observed light-induced changes in the $\mathrm{Mb}$ terminal's scotopic responses under conditions that prevented S-nitrosylation by including NEM (1 mM) in the recording pipette. We found that, in the presence of NEM, the latency of dim scotopic green responses $\left(1.6 \times 10^{7}\right.$ photons $\left./ \mathrm{cm}^{2} / \mathrm{s}\right)$ was slightly increased in 3 of 4 experiments (Fig. 10Ai,Aii) and was reduced in 1 of 4 experiments after a bright scotopic $\left(2.4 \times 10^{8}\right.$ photons/ $\mathrm{cm}^{2} / \mathrm{s}$ ) green flash (Fig. 10Aiii). On average, no significant change was detected (control: $243.04 \pm 19.09 \mathrm{~ms}$ vs second: $246.06 \pm 16.05 \mathrm{~ms}, n=4$; Fig. 10Aiii; $p=0.6$, paired Student's $t$ test). To test whether a photopic-sensitizing stimulus also alters 
Ai

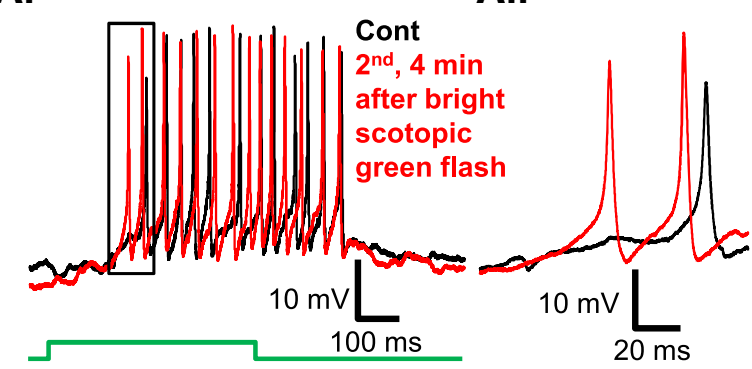

$1.6 \times 10^{7}$ photons $/ \mathrm{cm}^{2} / \mathrm{s}$

$\mathrm{Bi}$

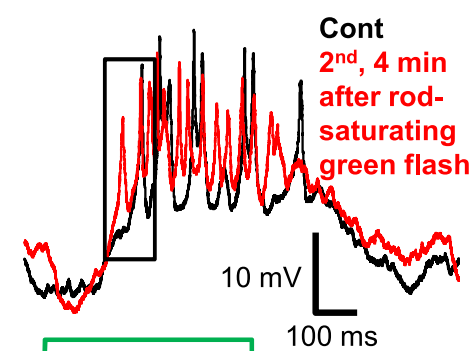

$1.6 \times 10^{7}$ photons $/ \mathrm{cm}^{2} / \mathrm{s}$

Ci

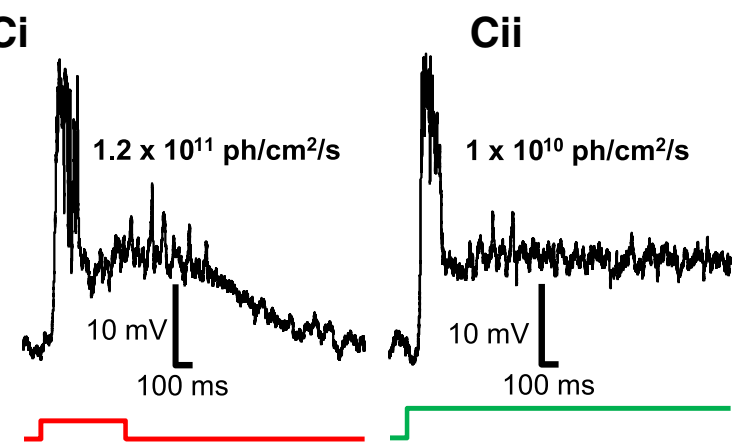

Aiii

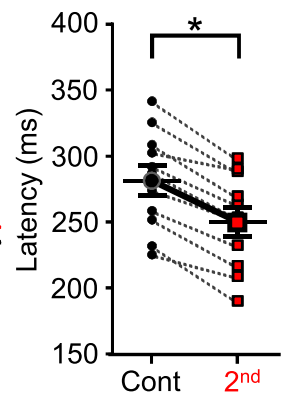

Biii

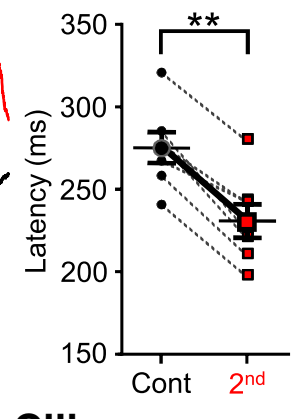

Ciii

$1.2 \times 10^{11} \mathrm{ph} / \mathrm{cm}^{2} / \mathrm{s}$

$5 \times 10^{13} \mathrm{ph} / \mathrm{cm}^{2} / \mathrm{s}$

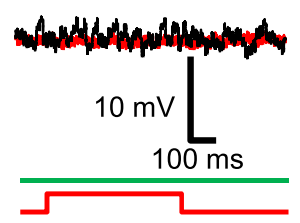

Figure 9. Scotopic light responses of $\mathrm{Mb}$ axon terminals can be modulated by light through rod-specific pathways. $\boldsymbol{A i}$, Rodmediated responses recorded from the axon terminal of an intact Mb to a full-field light flash ( $500 \mathrm{~ms}$ ) of scotopic green $(\lambda=505$ $\mathrm{nm}, 1.6 \times 10^{7}$ photons $\left./ \mathrm{cm}^{2} / \mathrm{s}\right)$ before (black) and $4 \mathrm{~min}$ after (red) a bright scotopic green $\left(\lambda=505 \mathrm{~nm}, 2.4 \times 10^{8}\right.$ photons/ $\mathrm{cm}^{2} / \mathrm{s}$ ) full-field light flash $(500 \mathrm{~ms}$ ). After stimulation with the bright scotopic green light, the repeated dim green stimulus evoked a spiking response with decreased latency compared with control. Membrane potentials at the beginning of the traces are $-51.9 \mathrm{mV}$ (red) and $-49.2 \mathrm{mV}$ (black). Aii, Enlargement of boxed area in Ai illustrating the decreased latency of rod-mediated, light-induced $\mathrm{Ca}^{2+}$ spikes when the green scotopic stimulus is increased by one order of magnitude. Membrane potentials at the beginning of the traces are $-49.5 \mathrm{mV}$ (red) and $-48.9 \mathrm{mV}$ (black). Aiii, Summary graph showing paired comparison of latency to first spike triggered by dim green $\left(505 \mathrm{~nm}, 1.6 \times 10^{7}\right.$ photons $\left./ \mathrm{cm}^{2} / \mathrm{s}\right)$ flash before and after presentation of sensitizing green light $\left(505 \mathrm{~nm}, 2.4 \times 10^{8}\right.$ photons $\left./ \mathrm{cm}^{2} / \mathrm{s}\right)$ recorded from different $\mathrm{Mb}$ terminals. The latency to first spike was significantly reduced for the second stimulus, on average by $31.25 \pm 3.12 \mathrm{~ms}$. Black circles represent control; red squares represent second scotopic response latency. ${ }^{* *} p=0.0001$ (paired Student's t test). $n=11$. Data are mean \pm SEM. $\boldsymbol{B i}$, Responses of an Mb terminal evoked by a scotopic green $\left(505 \mathrm{~nm}, 1.6 \times 10^{7}\right.$ photons $\left./ \mathrm{cm}^{2} / \mathrm{s}\right)$ light flash $(500 \mathrm{~ms})$ of a dark-adapted retina (black) were modulated by a rod-saturating bright green $\left(500 \mathrm{~ms}, 505 \mathrm{~nm}, 1.0 \times 10^{10}\right.$ photons $\left./ \mathrm{cm}^{2} / \mathrm{s}\right)$ light flash. Four minutes after the bright green flash, a repeated dim green stimulus evoked a spiking response with decreased latency (red) compared with control. Membrane potential at the beginning of the trace was $-47.14 \mathrm{mV}$ (red) and $-49.47 \mathrm{mV}$ (black). Bii, Enlargement of boxed area in Bi illustrating the decrease in latency observed in scotopic green light-evoked $\mathrm{Ca}^{2+}$ spikes after rod saturating green light stimulation. Membrane potentials at the beginning of the traces are $-48.79 \mathrm{mV}$ (red) and $-48.92 \mathrm{mV}$ (black). Biii, Summary graph showing paired comparison of latency to first spike triggered by dim green $\left(505 \mathrm{~nm}, 1.6 \times 10^{7}\right.$ photons $\left./ \mathrm{cm}^{2} / \mathrm{s}\right)$ flash before and after presentation of bright green light $\left(505 \mathrm{~nm}, 1.0 \times 10^{10}\right.$ photons $\left./ \mathrm{cm}^{2} / \mathrm{s}\right)$. The latency to first spike was significantly reduced for the second stimulus, on average by $44.44 \pm 4.71 \mathrm{~ms}$. Black circles represent control; red squares represent second scotopic response latency. ${ }^{* *} p=0.00008$ (paired Student's $t$ test). $n=7$. Data are mean \pm SEM. Ci, Responses recorded from an Mb terminal evoked by a weak photopic red flash $\left(500 \mathrm{~ms}, \lambda=660 \mathrm{~nm}, 1.2 \times 10^{11}\right.$ photons $\left./ \mathrm{cm}^{2} / \mathrm{s}\right)$. Membrane potential at the beginning of the trace is $-50.5 \mathrm{mV}$. Cii, Response from the same Mb axon terminal evoked by a sustained presentation of rod saturating green light $(\lambda=$ $505 \mathrm{~nm}, 1.0 \times 10^{10}$ photons $/ \mathrm{cm}^{2} / \mathrm{s}$ ). Membrane potential at the beginning of the trace is $-50.9 \mathrm{mV}$. Ciii, Neither weak photopic $\left(1.2 \times 10^{11}\right.$ photons $\left./ \mathrm{cm}^{2} / \mathrm{s}\right)$ nor brighter $\left(5 \times 10^{13}\right.$ photons $/ \mathrm{cm}^{2} / \mathrm{s}$, applied 9 min later $)$ red flash $(500 \mathrm{~ms}, \lambda=660 \mathrm{~nm})$ evoked measurable responses in $\mathrm{Mb}$ terminals (black and red traces, respectively) when applied on top of sustained rod-saturating green background illumination $\left(\lambda=505 \mathrm{~nm}, 1.0 \times 10^{10}\right.$ photons $\left./ \mathrm{cm}^{2} / \mathrm{s}\right)$. Membrane potentials at the beginning of the traces are $-40.3 \mathrm{mV}$ (black) and $-43.9 \mathrm{mV}$ (red).

the scotopic response latency in $\mathrm{Mb}$ terminals in an NEM-sensitive manner, we performed a similar experiment using 500-ms-long flashes of bright red $(\lambda=$ $660 \mathrm{~nm}$ ) light with intensity of $5 \times 10^{13}$ photons $/ \mathrm{cm}^{2} / \mathrm{s}$ to sensitize scotopic green flash $\left(4.2 \times 10^{7}\right.$ photons $\left./ \mathrm{cm}^{2} / \mathrm{s}\right)$ responses. In the presence of intracellular NEM (1 $\mathrm{mM}$ ), no reduction of spike latency was observed in response to scotopic green stimulations (Fig. 10Bi,Bii) in any tested cell $(n=$ 3) (Fig. 10Biii; $p=0.1$, paired Student's $t$ test). However, there is reduction of lightevoked $\mathrm{Ca}^{2+}$ spikes in the presence of intracellular NEM in both sets of experiment (Fig. 10Ai,Bi), indicating a possible inhibitory NEM effect on dendritic signaling in addition to preventing S-nitrosylation in intact Mbs (Shapiro et al., 1994). It is important to note that light-induced modulation of rod-mediated dim light responses recorded at the $\mathrm{Mb}$ terminals could be influenced by multiple upstream NO-mediated processes acting on (1) rods (Kurenny et al., 1994), (2) cones (Savchenko et al., 1997), and/or (3) horizontal cells (Baldridge and Fischer, 2001), making the use of NOS inhibitor TRIM in these experiments inappropriate. Nonetheless, it is unlikely that the NO-mediated, cGMP-dependent increase in Mb sensitivity for weak inputs (Snellman and Nawy, 2004) played a role in modulation of dim light responses because, unlike in horizontal cells, NO donor failed to visibly increase cGMP levels in Mb terminals in the goldfish retina, even in the presence of PDE blocker (Baldridge and Fischer, 2001).

\section{Discussion}

The present study describes a novel NOdependent modulatory mechanism that alters the output of Mb-type BCs. The major findings of this investigation were as follows: (1) $\mathrm{Ca}^{2+}$ spike threshold in $\mathrm{Mb}$ terminals is subject to activity-dependent plasticity; (2) glutamate released by strong depolarization of a single $\mathrm{Mb}$ terminal is sufficient to trigger generation and delivery of $\mathrm{NO}$; (3) $\mathrm{NO}$ can act in a retrograde manner to lower $\mathrm{I}_{\mathrm{Ca}}$ threshold in strongly stimulated $\mathrm{Mb}$ terminals via an NEM-sensitive S-nitrosylation mechanism; (4) Mb terminals subjected to endogenous or exogenous NO show weighted potentiation: they respond to weak depolarizing inputs with enhanced glutamate output while maintaining inputoutput ratio (gain) for strong stimuli; and (5) exposure to light with intensity $\geq 2.4 \times$ $10^{8}$ photons $/ \mathrm{cm}^{2} / \mathrm{s}$ induced weighted potentiation of scotopic responses in $\mathrm{Mb}$ terminals (expressed as reduced $\mathrm{Ca}^{2+}$ spike delay) in an NEM-sensitive manner. 


\section{NO modulation of retinal signaling}

In vertebrate retinas, $\mathrm{NO}$ is synthetized mainly by the neuronal-type NO synthase (Dawson et al., 1991; Tsumamoto et al., 2002), although endothelial (Haverkamp et al., 1999) as well as the inducible (Palamalai et al., 2006) types are also present. Extensive investigations using immunohistochemistry and in situ hybridization detected these enzymes in subtypes of all retinal cell classes with species-dependent patterns (Vielma et al., 2012). The best known retinal effect of NO is the uncoupling of gap junctions between horizontal cells in a variety of species (DeVries and Schwartz, 1989; Lu and McMahon, 1997; Daniels and Baldridge, 2011) that is mediated by increased intracellular cGMP via soluble guanylate cyclase. Similarly, gap junctions between AII ACs and BCs are regulated by $\mathrm{NO}$ in a cGMP-dependent manner (Mills and Massey, 1995). Indeed, a number of reports demonstrated increased retinal cGMP synthesis in response to NO donor application (Blute et al., 1998; Gotzes et al., 1998; Baldridge and Fischer, 2001; Sáenz et al., 2002). In addition, NO-triggered increases in cGMP can open CNGCs and in turn trigger transmitter release from cones in salamander (Rieke and Schwartz, 1994) and lizard (Savchenko et al., 1997) retinas.

Not all actions of NO are mediated through cGMP-dependent pathways in the retina: $\mathrm{NO}$ was shown to modulate $\mathrm{I}_{\mathrm{Ca}}$ of rods in salamander independent of cGMP (Kurenny et al., 1994). Most interestingly, the activation threshold of $\mathrm{I}_{\mathrm{Ca}}$ in salamander rods was shifted to the left, resulting in a decrease of $\mathrm{V}_{1 / 2}$ by $-4.3 \pm$ $0.6 \mathrm{mV}$ (Kurenny et al., 1994). Those results are strikingly similar to our data (Fig. $6 \mathrm{~A}, \mathrm{~V}_{50 \%}$ : -5.5 mV); thus, our findings and conclusions support the speculation of Kurenny et al. (1994), suggesting S-nitrosylation as a possible mechanism by which $\mathrm{NO}$ could alter $\mathrm{I}_{\mathrm{Ca}}$ threshold in salamander rods. The similarities between the results of the two studies suggest that $\mathrm{I}_{\mathrm{Ca}}$ modulation through NO-triggered S-nitrosylation reactions could be a ubiquitous regulatory process in the vertebrate retina.

\section{Can NO-mediated S-nitrosylation in Mbs occur under} physiological conditions?

Direct nitrosylation of thiol side-chains of cysteine residues by NO plays an important role in numerous physiological processes by triggering dynamic conformational changes, which affect protein-protein interactions or influence protein location (Ahern et al., 2002). Yet, S-nitrosylation in the nervous system is particularly characteristic during periods of oxidative stress and in neurodegenerative diseases in which NO levels are elevated (Nakamura et al., 2013). We were able to trigger this NO pathway by endogenous synaptic glutamate, released from a single presynaptic terminal, which resulted in the retrograde modulation of $\mathrm{I}_{\mathrm{Ca}}$ through $\mathrm{S}$-nitrosylation reactions at the same presynaptic $\mathrm{Mb}$ terminals.
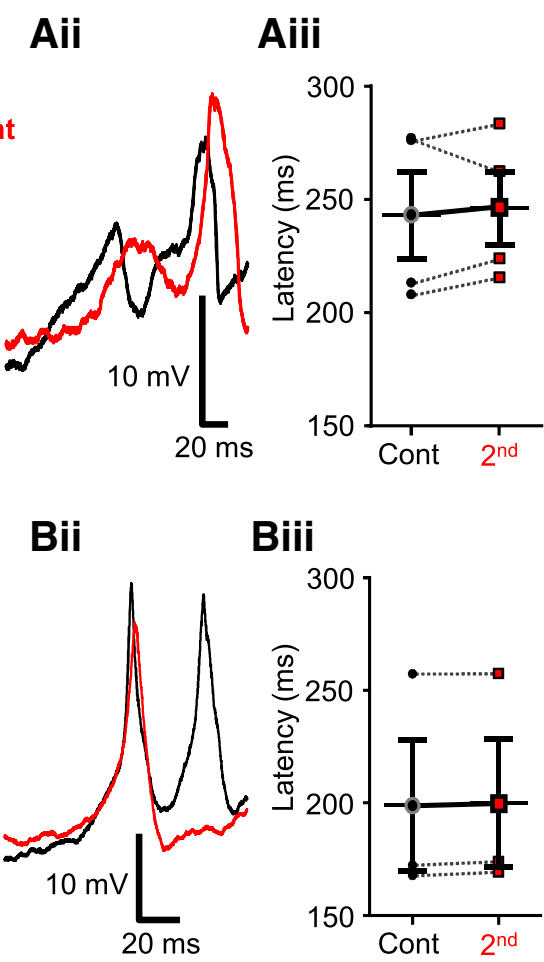

Figure 10. Both bright scotopic and photopic light induced modulation of scotopic light responses in Mb terminals in an scotopic green flash $\left(500 \mathrm{~ms}, \lambda=505 \mathrm{~nm}, 2.4 \times 10^{8}\right.$ photons $/ \mathrm{cm}^{2} / \mathrm{s}$ ) in the presence of NEM. Black circles represent control; red squares represent second scotopic response latency; $n=4$. Bi, When NEM (1 mM) was included in the pipette solution the bright responses $\left(505 \mathrm{~nm}, 4.2 \times 10^{7}\right.$ photons $/ \mathrm{cm}^{2} / \mathrm{s}$ ) compared before and $5 \mathrm{~min}$ after bright red flash in the presence of NEM. Black circles represent control; red squares represent second scotopic response latency; $n=3$. Data are mean $\pm \mathrm{SEM}$.

However, the depolarizing ramp protocols that were proven to trigger this pathway, and in turn consistently shifted $\mathrm{I}_{\mathrm{Ca}}$ threshold in an NEM-sensitive manner (Figs. 1 and $2 \mathrm{Bi}, \mathrm{Bii}$ ), were robust, and $\mathrm{Mb}$ terminals were depolarized far above their physiologically relevant maximal membrane potential $(\sim-20 \mathrm{mV})$ (Saito and Kujiraoka, 1982; Protti et al., 2000). Importantly, we were able to trigger changes in $\operatorname{dim}\left(\sim 10^{7}\right.$ photons $\left./ \mathrm{cm}^{2} / \mathrm{s}\right)$ light-evoked $\mathrm{Ca}^{2+}$ spike responses of $\mathrm{Mb}$ terminals by brighter $\left(\geq 2.4 \times 10^{8}\right.$ photons $\left./ \mathrm{cm}^{2} / \mathrm{s}\right)$ light: the sensitizing bright light decreased the latency of the first light-evoked $\mathrm{Ca}^{2+}$ spike in an NEM-sensitive manner (Fig. 10), consistent with a light-evoked decrease in $\mathrm{I}_{\mathrm{Ca}}$ activation threshold through S-nitrosylation reactions.

Precise measurement of increases in membrane capacitance associated with our standard voltage ramp protocol was problematic because of the long tail currents (Gillis, 2000); but based on our best measurements $(n=3)$, it was $\sim 350 \mathrm{fF}$. Direct measurement of light-evoked membrane capacitance increase of intact Mbs is also complicated because of their complex morphology (Mennerick et al., 1997) and the slowly decaying lightevoked synaptic conductances (Saito and Kujiraoka, 1982). 
However, when membrane potential waveforms triggered by 500 ms bright red light flash (similar to the ones used to "sensitize" the Mb terminals; Fig. $8 B i, B i i, D)$ recorded from the axon terminal of intact Mbs were used as command potentials of voltageclamp protocols in separate experiments, they triggered membrane capacitance increase of $275 \pm 48 \mathrm{fF}(n=10)$ in axotomized $\mathrm{Mb}$ terminals (Lipin and Vigh, 2013). Therefore, the magnitude of depolarizing ramp-evoked glutamate release appears to be comparable with that triggered by bright light stimuli from Mbs.

\section{Consequences of NO-mediated weighted potentiation for glutamate release from $\mathrm{Mb}$ terminals}

Numerous neurotransmitters inhibit presynaptic $\mathrm{I}_{\mathrm{Ca}}$ via G-protein coupled receptors by inducing changes in the voltage dependence of $\mathrm{I}_{\mathrm{Ca}}$, resulting in channel activation at more depolarized potentials (Bean, 1989). Shifting the activation threshold of $\mathrm{I}_{\mathrm{Ca}}$ to more depolarized potentials is an extremely potent way of reducing transmitter release (Catterall and Few, 2008) because of the power law of synaptic transmission (Katz and Miledi, 1970). Less is known about positive modulation of $\mathrm{I}_{\mathrm{Ca}}$ by transmitters; to this end, only the neurosteroid pregnenolone sulfate was shown to potentiate presynaptic release at the calyx of Held by a mechanism that involved shifting $\mathrm{I}_{\mathrm{Ca}}$ activation to the left (Hige et al., 2006). Despite the extensive literature published on activity-dependent short- and long-term synaptic plasticity in the CNS, to date only one reference described activity-dependent positive modulation of presynaptic $\mathrm{I}_{\mathrm{Ca}}$ activation: at the calyx of Held synapse, tetanic stimulation shifted the half-activation voltage $\left(\mathrm{V}_{1 / 2}\right)$ of the presynaptic $\mathrm{I}_{\mathrm{Ca}}$ by $-4.1 \mathrm{mV}$ (Cuttle et al., 1998), analogous to our results. Although the underlying mechanism was not identified beyond establishing that it was independent of G-proteins, Cuttle et al. (1998) showed that a small shift in $\mathrm{I}_{\mathrm{Ca}}$ activation to more negative potentials can significantly increase transmitter output from the presynaptic calyx, which is entirely consistent with our data (Fig. 6A, $C, F$ ).

Although $\mathrm{Mb}$ terminals release glutamate at ribbon synapses, which are specialized to release transmitters continuously over long periods and capable to code changes in illumination rather quickly (Sterling and Matthews, 2005; Thoreson, 2007), they are subject to short-term synaptic plasticity known as paired pulse depression of glutamate release (von Gersdorff and Matthews, 1997). Activity-dependent long-term potentiation of the BC $\rightarrow$ GC synapse has also been shown in the developing zebrafish retina (Wei et al., 2012), although this phenomenon disappears with maturation. Activity-dependent short-term potentiation of release seen at central synapses (Habets and Borst, 2006) from Mb or other BCs has not been reported so far. Importantly, the effect of the left-shifted $\mathrm{I}_{\mathrm{Ca}}$ activation on the input-output ratio of Mbs is very unique: this weighted potentiation not only enhanced $\mathrm{I}_{\mathrm{Ca}}$ triggered by weak inputs, but the enhancement gradually decreased as the input strength increased, limiting the potentiation to the physiologically relevant membrane potentiation range. The power law of synaptic transmission (Katz and Miledi, 1970) and the particularly high level of $\mathrm{Ca}^{2+}$ cooperativity in mediating release from $\mathrm{Mb}$ terminals (Heidelberger et al., 1994) further magnify this phenomenon at the level of glutamate output from $\mathrm{Mb}$ terminals: NO-mediated increase of $\mathrm{I}_{\mathrm{Ca}}$ resulted in increased exocytosis at $-30 \mathrm{mV}$; however, the small (yet significant) increase in $\mathrm{I}_{\mathrm{Ca}}$ amplitude at $-20 \mathrm{mV}$ did not cause consequent $\Delta \mathrm{C}_{\mathrm{m}}$ increase (Fig. 6D,F).

Intrinsic adaptation to luminance is mediated through synaptic depression of glutamate release from rod BCs (Oesch and
Diamond, 2011), resulting in $\mathrm{Ca}^{2+}$ channel inactivation and vesicle depletion (Jarsky et al., 2011). It is unclear whether the rod-driven circuitry in the mammalian retina is subject to NO-mediated or other types of synaptic potentiation. Nonetheless, mammalian ON cone BCs show NO-dependent, cGMPmediated weighted sensitization: upon NO donor exposure, their response to weak stimuli increased, whereas responses to strong inputs remained unaltered (Snellman and Nawy, 2004). We discovered a novel form of activity-dependent, NO-mediated synaptic plasticity expressed at the axon terminal of the roddominated Mb-type bipolar cell: it is triggered by large depolarization and, through synaptic communication, it causes positive modulation of voltage-gated $\mathrm{Ca}^{2+}$ channels, particularly in response to consecutive weak inputs. Because Mbs in the fish retina make direct synaptic contacts with GCs (Witkovsky and Dowling, 1969; Marc and Liu, 2000; Palmer, 2010), we propose that this novel mechanism enhances the representation of weak rod signals at $\mathrm{Mb} \rightarrow \mathrm{GC}$ synapses under bright scotopic and mesopic light conditions. The selective potentiation of weak signals may counter use-dependent depression of glutamate release from BCs during light adaptation and prevent the loss of critical visual information carried by dim scotopic signals.

\section{References}

Ahern GP, Klyachko VA, Jackson MB (2002) cGMP and S-nitrosylation: two routes for modulation of neuronal excitability by NO. Trends Neurosci 25:510-517. CrossRef Medline

Baccus SA, Meister M (2002) Fast and slow contrast adaptation in retinal circuitry. Neuron 36:909-919. CrossRef Medline

Baden T, Esposti F, Nikolaev A, Lagnado L (2011) Spikes in retinal bipolar cells phase-lock to visual stimuli with millisecond precision. Curr Biol 21:1859-1869. CrossRef Medline

Baden T, Berens P, Bethge M, Euler T (2013a) Spikes in mammalian bipolar cells support temporal layering of the inner retina. Curr Biol 23:48-52. CrossRef Medline

Baden T, Euler T, Weckström M, Lagnado L (2013b) Spikes and ribbon synapses in early vision. Trends Neurosci 36:480-488. CrossRef Medline

Baldridge WH, Fischer AJ (2001) Nitric oxide donor stimulated increase of cyclic GMP in the goldfish retina. Vis Neurosci 18:849-856. Medline

Bean BP (1989) Neurotransmitter inhibition of neuronal calcium currents by changes in channel voltage dependence. Nature 340:153-156. CrossRef Medline

Blute TA, Velasco P, Eldred WD (1998) Functional localization of soluble guanylate cyclase in turtle retina: modulation of cGMP by nitric oxide donors. Vis Neurosci 15:485-498. Medline

Burrone J, Neves G, Gomis A, Cooke A, Lagnado L (2002) Endogenous calcium buffers regulate fast exocytosis in the synaptic terminal of retinal bipolar cells. Neuron 33:101-112. CrossRef Medline

Busskamp V, Duebel J, Balya D, Fradot M, Viney TJ, Siegert S, Groner AC, Cabuy E, Forster V, Seeliger M, Biel M, Humphries P, Paques M, Mohand-Said S, Trono D, Deisseroth K, Sahel JA, Picaud S, Roska B (2010) Genetic reactivation of cone photoreceptors restores visual responses in retinitis pigmentosa. Science 329:413-417. CrossRef Medline

Catterall WA, Few AP (2008) Calcium channel regulation and presynaptic plasticity. Neuron 59:882-901. CrossRef Medline

Cuttle MF, Tsujimoto T, Forsythe ID, Takahashi T (1998) Facilitation of the presynaptic calcium current at an auditory synapse in rat brainstem. J Physiol 512:723-729. CrossRef Medline

Damodaran VB, Place LW, Kipper MJ, Reynolds MM (2012) Enzymatically degradable nitric oxide releasing S-nitrosated dextran thiomers for biomedical applications. J Mater Chem 22:23038-23048. CrossRef

Daniels BA, Baldridge WH (2011) The light-induced reduction of horizontal cell receptive field size in the goldfish retina involves nitric oxide. Vis Neurosci 28:137-144. CrossRef Medline

Dawson TM, Bredt DS, Fotuhi M, Hwang PM, Snyder SH (1991) Nitricoxide synthase and neuronal NADPH diaphorase are identical in brain and peripheral-tissues. Proc Natl Acad Sci U S A 88:7797-7801. CrossRef Medline 
Demb JB (2002) Multiple mechanisms for contrast adaptation in the retina. Neuron 36:781-783. CrossRef Medline

DeVries SH, Schwartz EA (1989) Modulation of an electrical synapse between solitary pairs of catfish horizontal cells by dopamine and 2nd messengers. J Physiol 414:351-375. Medline

Dowling JE (1987) The retina: an approachable part of the brain. Cambridge, MA: Belknap.

Dreosti E, Esposti F, Baden T, Lagnado L (2011) In vivo evidence that retinal bipolar cells generate spikes modulated by light. Nat Neurosci 14:951952. CrossRef Medline

Eldred WD, Blute TA (2005) Imaging of nitric oxide in the retina. Vision Res 45:3469-3486. CrossRef Medline

Feng Y, Yu S, Lasell TK, Jadhav AP, Macia E, Chardin P, Melancon P, Roth M, Mitchison T, Kirchhausen T (2003) Exol: a new chemical inhibitor of the exocytic pathway. Proc Natl Acad Sci U S A 100:6469-6474. CrossRef Medline

Gillis KD (2000) Admittance-based measurement of membrane capacitance using the EPC-9 patch-clamp amplifier. Pflugers Arch 439:655664. CrossRef Medline

Giove TJ, Deshpande MM, Eldred WD (2009) Identification of alternate transcripts of neuronal nitric oxide synthase in the mouse retina. J Neurosci Res 87:3134-3142. CrossRef Medline

Gotzes S, de Vente J, Müller F (1998) Nitric oxide modulates cGMP levels in neurons of the inner and outer retina in opposite ways. Vis Neurosci 15:945-955. Medline

Griguer C, Fuchs PA (1996) Voltage-dependent potassium currents in cochlear hair cells of the embryonic chick. J Neurophysiol 75:508-513. Medline

Habets RL, Borst JG (2006) An increase in calcium influx contributes to post-tetanic potentiation at the rat calyx of held synapse. J Neurophysiol 96:2868-2876. CrossRef Medline

Haverkamp S, Kolb H, Cuenca N (1999) Endothelial nitric oxide synthase (eNOS) is localized to Müller cells in all vertebrate retinas. Vision Res 39:2299-2303. CrossRef Medline

Haverkamp S, Specht D, Majumdar S, Zaidi NF, Brandstätter JH, Wasco W, Wässle H, Tom Dieck S (2008) Type 4 OFF cone bipolar cells of the mouse retina express calsenilin and contact cones as well as rods. J Comp Neurol 507:1087-1101. CrossRef Medline

Hayashida Y, Rodríguez CV, Ogata G, Partida GJ, Oi H, Stradleigh TW, Lee SC, Colado AF, Ishida AT (2009) Inhibition of adult rat retinal ganglion cells by D1-type dopamine receptor activation. J Neurosci 29:1500115016. CrossRef Medline

Heidelberger R, Matthews G (1992) Calcium influx and calcium current in single synaptic terminals of goldfish retinal bipolar neurons. J Physiol 447:235-256. Medline

Heidelberger R, Heinemann C, Neher E, Matthews G (1994) Calcium dependence of the rate of exocytosis in a synaptic terminal. Nature 371:513515. CrossRef Medline

Henry D, Burke S, Shishido E, Matthews G (2003) Retinal bipolar neurons express the cyclic nucleotide-gated channel of cone photoreceptors. J Neurophysiol 89:754-761. CrossRef Medline

Hige T, Fujiyoshi Y, Takahashi T (2006) Neurosteroid pregnenolone sulfate enhances glutamatergic synaptic transmission by facilitating presynaptic calcium currents at the calyx of Held of immature rats. Eur J Neurosci 24:1955-1966. CrossRef Medline

Hille B (2001) Voltage-dependent gates have gating charge and gating current. In: Ion channels of excitable membranes, pp 56-59. Sunderland, MA: Sinauer.

Hirasawa H, Kaneko A (2003) pH changes in the invaginating synaptic cleft mediate feedback from horizontal cells to cone photoreceptors by modulating $\mathrm{Ca}^{2+}$ channels. J Gen Physiol 122:657-671. CrossRef Medline

Hirooka K, Kourennyi DE, Barnes S (2000) Calcium channel activation facilitated by nitric oxide in retinal ganglion cells. J Neurophysiol 83:198206. Medline

Hrabie JA, Klose JR, Wink DA, Keefer LK (1993) New nitric oxide-releasing zwitterions derived from polyamines. J Org Chem 58:1472-1476. CrossRef

Jarsky T, Cembrowski M, Logan SM, Kath WL, Riecke H, Demb JB, Singer JH (2011) A synaptic mechanism for retinal adaptation to luminance and contrast. J Neurosci 31:11003-11015. CrossRef Medline

Joselevitch C, Kamermans M (2007) Interaction between rod and cone in- puts in mixed-input bipolar cells in goldfish retina. J Neurosci Res 85: 1579-1591. CrossRef Medline

Joselevitch C, Kamermans M (2009) Retinal parallel pathways: seeing with our inner fish. Vision Res 49:943-959. CrossRef Medline

Kaneko A, Tachibana M (1985) A voltage-clamp analysis of membrane currents in solitary bipolar cells dissociated from carassius-auratus. J Physiol 358:131-152. Medline

Kastner DB, Baccus SA (2011) Coordinated dynamic encoding in the retina using opposing forms of plasticity. Nat Neurosci 14:1317-1322. CrossRef Medline

Katz B, Miledi R (1970) Further study of the role of calcium in synaptic transmission. J Physiol 207:789-801. Medline

Kim KJ, Rieke F (2001) Temporal contrast adaptation in the input and output signals of salamander retinal ganglion cells. J Neurosci 21:287-299. Medline

Krizaj D (2000) Mesopic state: cellular mechanisms involved in pre- and post-synaptic mixing of rod and cone signals. Microsc Res Tech 50:347359. CrossRef Medline

Kurenny DE, Moroz LL, Turner RW, Sharkey KA, Barnes S (1994) Modulation of ion channels in rod photoreceptors by nitric-oxide. Neuron 13:315-324. CrossRef Medline

Leuranguer V, Dirksen RT, Beam KG (2003) Potentiated L-type Ca ${ }^{2+}$ channels rectify. J Gen Physiol 121:541-550. CrossRef Medline

Lipin M, Vigh J (2013) Quantifying the effect of light activated outer and inner retinal inhibitory pathways on exocytosis from mixed bipolar cells. ARVO meeting, Seattle WA. Invest Opthalmol Vis Sci 540: E-Abstract 6155.

Loew ER, McFarland WN (1990) The underwater visual environment. In: The visual system of fish (Douglas RH, Djamgoz MBA, eds), pp 1-43. New York: Chapman and Hall.

Logiudice L, Henry D, Matthews G (2006) Identification of calcium channel alphal subunit mRNA expressed in retinal bipolar neurons. Mol Vis 12 : 184-189. Medline

Lu C, McMahon DG (1997) Modulation of hybrid bass retinal gap junctional channel gating by nitric oxide. J Physiol 499:689-699. Medline

Maragos CM, Morley D, Wink DA, Dunams TM, Saavedra JE, Hoffman A, Bove AA, Isaac L, Hrabie JA, Keefer LK (1991) Complexes of .NO with nucleophiles as agents for the controlled biological release of nitric oxide: vasorelaxant effects. J Med Chem 34:3242-4247. CrossRef Medline

Marc RE, Liu W (2000) Fundamental GABAergic amacrine cell circuitries in the retina: nested feedback, concatenated inhibition, and axosomatic synapses. J Comp Neurol 425:560-582. CrossRef Medline

Marty A, Neher E (1995) Tight-seal whole-cell recording. In: Single-channel recording (Sakmann B, Neher E, eds), pp 31-52. New York: Plenum.

McFarland WN, Munz FW (1975) Part II: the photic environment of clear tropical seas during the day. Vision Res 15:1063-1070. CrossRef Medline

Mennerick S, Matthews G (1998) Rapid calcium-current kinetics in synaptic terminals of goldfish retinal bipolar neurons. Vis Neurosci 15:10511056. CrossRef Medline

Mennerick S, Zenisek D, Matthews G (1997) Static and dynamic membrane properties of large-terminal bipolar cells from goldfish retina: experimental test of a compartment model. J Neurophysiol 78:51-62. Medline

Mills SL, Massey SC (1995) Differential properties of 2 gap junctional pathways made by AII amacrine cells. Nature 377:734-737. CrossRef Medline

Munz FW, McFarland WN (1973) The significance of spectral position in the rhodopsins of tropical marine fishes. Vision Res 13:1829-1874. CrossRef Medline

Nakamura T, Tu S, Akhtar MW, Sunico CR, Okamoto S, Lipton SA (2013) Aberrant protein s-nitrosylation in neurodegenerative diseases. Neuron 78:596-614. CrossRef Medline

Neher E (1998) Vesicle pools and $\mathrm{Ca}^{2+}$ microdomains: new tools for understanding their roles in neurotransmitter release. Neuron 20:389-399. CrossRef Medline

Nikolaev A, Leung KM, Odermatt B, Lagnado L (2013) Synaptic mechanisms of adaptation and sensitization in the retina. Nat Neurosci 16:934941. CrossRef Medline

Oesch NW, Diamond JS (2011) Ribbon synapses compute temporal contrast and encode luminance in retinal rod bipolar cells. Nat Neurosci 14:1555-1561. CrossRef Medline

Palamalai V, Darrow RM, Organisciak DT, Miyagi M (2006) Light-induced changes in protein nitration in photoreceptor rod outer segments. Mol Vis 12:1543-1551. Medline 
Palmer MJ (2006) Modulation of $\mathrm{Ca}^{2+}$-activated $\mathrm{K}+$ currents and $\mathrm{Ca}^{2+}$ dependent action potentials by exocytosis in goldfish bipolar cell terminals. J Physiol 572:747-762. CrossRef Medline

Palmer MJ (2010) Characterization of bipolar cell synaptic transmission in goldfish retina using paired recordings. J Physiol 588:1489-1498. CrossRef Medline

Palmer MJ, Taschenberger H, Hull C, Tremere L, von Gersdorff H (2003) Synaptic activation of presynaptic glutamate transporter currents in nerve terminals. J Neurosci 23:4831-4841. Medline

Pang JJ, Gao F, Lem J, Bramblett DE, Paul DL, Wu SM (2010) Direct rod input to cone $\mathrm{BCs}$ and direct cone input to rod $\mathrm{BCs}$ challenge the traditional view of mammalian BC circuitry. Proc Natl Acad Sci U S A 107: 395-400. CrossRef Medline

Ping Y, Huang H, Zhang XJ, Yang XL (2008) Melatonin potentiates rod signals to ON type bipolar cells in fish retina. J Physiol 586:2683-2694. CrossRef Medline

Protti DA, Flores-Herr N, von Gersdorff H (2000) Light evokes $\mathrm{Ca}^{2+}$ spikes in the axon terminal of a retinal bipolar cell. Neuron 25:215-227. CrossRef Medline

Protti DA, Flores-Herr N, Li W, Massey SC, Wässle H (2005) Light signaling in scotopic conditions in the rabbit, mouse and rat retina: a physiological and anatomical study. J Neurophysiol 93:3479-3488. CrossRef Medline

Rieke F (2001) Temporal contrast adaptation in salamander bipolar cells. J Neurosci 21:9445-9454. Medline

Rieke F, Rudd ME (2009) The challenges natural images pose for visual adaptation. Neuron 64:605-616. CrossRef Medline

Rieke F, Schwartz EA (1994) A cGMP-gated current can control exocytosis at cone synapses. Neuron 13:863-873. CrossRef Medline

Sáenz DA, Turjanski AG, Sacca GB, Marti M, Doctorovich F, Sarmiento MI, Estrin DA, Rosenstein RE (2002) Physiological concentrations of melatonin inhibit the nitridergic pathway in the Syrian hamster retina. J Pineal Res 33:31-36. CrossRef Medline

Sah P, Davies P (2000) Calcium-activated potassium currents in mammalian neurons. Clin Exp Pharmacol Physiol 27:657-663. CrossRef Medline

Saito T, Kujiraoka T (1982) Physiological and morphological identification of 2 types of on-center bipolar cells in the carp retina. J Comp Neurol 205:161-170. CrossRef Medline

Saito T, Kondo H, Toyoda JI (1979) Ionic mechanisms of 2 types of oncenter bipolar cells in the carp retina: 1 . Responses to central illumination. J Gen Physiol 73:73-90. CrossRef Medline

Sakaba T, Ishikane H, Tachibana M (1997) $\mathrm{Ca}^{2+}$-activated K+ current at presynaptic terminals of goldfish retinal bipolar cells. Neurosci Res 27: 219-228. CrossRef Medline

Saszik S, DeVries SH (2012) A mammalian retinal bipolar cell uses both graded changes in membrane voltage and all-or-nothing $\mathrm{Na}^{+}$spikes to encode light. J Neurosci 32:297-307. CrossRef Medline

Savchenko A, Barnes S, Kramer RH (1997) Cyclic-nucleotide-gated channels mediate synaptic feedback by nitric oxide. Nature 390:694-698. CrossRef Medline

Shapiro MS, Wollmuth LP, Hille B (1994) Modulation of $\mathrm{Ca}^{2+}$ channels by PTX-sensitive G-proteins is blocked by $\mathrm{N}$-ethylmaleimide in rat sympathetic neurons. J Neurosci 14:7109-7116. Medline

Singer JH, Diamond JS (2003) Sustained $\mathrm{Ca}^{2+}$ entry elicits transient postsynaptic currents at a retinal ribbon synapse. J Neurosci 23:10923-10933. Medline

Smirnakis SM, Berry MJ, Warland DK, Bialek W, Meister M (1997) Adaptation of retinal processing to image contrast and spatial scale. Nature 386:69-73. CrossRef Medline

Snellman J, Nawy S (2004) cGMP-dependent kinase regulates response sensitivity of the mouse on bipolar cell. J Neurosci 24:6621-6628. CrossRef Medline
Sterling P (2003) How retinal circuits optimize the transfer of visual information. In: The visual neurosciences (Chalupa LM, Werner JS, eds), pp 234-259. Cambridge, MA: MIT.

Sterling P, Matthews G (2005) Structure and function of ribbon synapses. Trends Neurosci 28:20-29. CrossRef Medline

Tachibana M (1999) Regulation of transmitter release from retinal bipolar cells. Prog Biophys Mol Biol 72:109-133. CrossRef Medline

Tachibana M, Kaneko A (1987) Gamma-aminobutyric-acid exerts a local inhibitory-action on the axon terminal of bipolar cells: evidence for negative feedback from amacrine cells. Proc Natl Acad Sci U S A 84:35013505. CrossRef Medline

Thoreson WB (2007) Kinetics of synaptic transmission at ribbon synapses of rods and cones. Mol Neurobiol 36:205-223. CrossRef Medline

Tsumamoto Y, Yamashita K, Takumida M, Okada K, Mukai S, Shinya M, Yamashita H, Mishima HK (2002) In situ localization of nitric oxide synthase and direct evidence of $\mathrm{NO}$ production in rat retinal ganglion cells. Brain Res 933:118-129. CrossRef Medline

Vergara C, Latorre R, Marrion NV, Adelman JP (1998) Calcium-activated potassium channels. Curr Opin Neurobiol 8:321-329. CrossRef Medline

Vielma AH, Retamal MA, Schmachtenberg O (2012) Nitric oxide signaling in the retina: what have we learned in two decades? Brain Res 1430:112125. CrossRef Medline

Vigh J, von Gersdorff H (2005) Prolonged reciprocal signaling via NMDA and GABA receptors at a retinal ribbon synapse. J Neurosci 25:1141211423. CrossRef Medline

Vigh J, Li GL, Hull C, von Gersdorff H (2005) Long-term plasticity mediated by mGluR1 at a retinal reciprocal synapse. Neuron 46:469-482. CrossRef Medline

Vigh J, Vickers E, von Gersdorff H (2011) Light-evoked lateral GABAergic inhibition at single bipolar cell synaptic terminals is driven by distinct retinal microcircuits. J Neurosci 31:15884-15893. CrossRef Medline

von Gersdorff H, Matthews G (1996) Calcium-dependent inactivation of calcium current in synaptic terminals of retinal bipolar neurons. J Neurosci 16:115-122. Medline

von Gersdorff H, Matthews G (1997) Depletion and replenishment of vesicle pools at a ribbon-type synaptic terminal. J Neurosci 17:1919-1927. Medline

Walraven J, Enroth-Cugell C, Hood DC, MacLeod DIA, Schnapf JL (1990) In visual perception: the neurophysiological foundations (Spillman L, Werner JZ, eds), pp 53-101 San Diego: Academic.

Wässle H (2004) Parallel processing in the mammalian retina. Nat Rev Neurosci 5:747-757. CrossRef Medline

Wei HP, Yao YY, Zhang RW, Zhao XF, Du JL (2012) Activity-induced longterm potentiation of excitatory synapses in developing zebrafish retina in vivo. Neuron 75:479-489. CrossRef Medline

Werblin FS, Dowling JE (1969) Organization of retina of mudpuppy necturus maculosus: 2. Intracellular recording. J Neurophysiol 32:339-355. Medline

Witkovsky P (2004) Dopamine and retinal function. Doc Ophthalmol 108: 17-40. CrossRef Medline

Witkovsky P, Dowling JE (1969) Synaptic relationships in the plexiform layers of carp retina. Z Zellforsch Mikrosk Anat 100:60-82. CrossRef Medline

Wong KY, Cohen ED, Dowling JE (2005) Retinal bipolar cell input mechanisms in giant danio: II. Patch-clamp analysis of ON bipolar cells. J Neurophysiol 93:94-107. CrossRef Medline

Wu SM (1994) Synaptic transmission in the outer retina. Annu Rev Physiol 56:141-168. CrossRef Medline

Zenisek D, Matthews G (1998) Calcium action potentials in retinal bipolar neurons. Vis Neurosci 15:69-75. Medline 